\title{
Light as a stressor and its impact on biotic and abiotic stress responses in plants
}

\author{
Venja Roeber ${ }^{1}$, Ishita Bajaj ${ }^{1}$, Mareike Rohde ${ }^{1}$, Thomas Schmulling ${ }^{2}$, and Anne Cortleven ${ }^{1}$ \\ ${ }^{1}$ Freie Universitat Berlin Institut fur Biologie \\ ${ }^{2}$ Affiliation not available
}

July 1, 2020

\begin{abstract}
Light is important for plant life as a source of energy to drive photosynthesis but also as an environmental signal regulating development or cellular events such as resetting of the circadian clock. Light itself can cause stress such as excess light, fluctuating light, photoperiod and ultraviolet light stress. Light quality, quantity and light duration are important sources of information to prepare plants for future light stress events. Recurring light stress results in acclimation processes to the changing light environment. Furthermore, light regulates the responses of plants to diverse biotic and abiotic stresses. For example, short day conditions or shady environments prime thermotolerance and increase cold acclimation. Similarly, during drought stress, light signaling is important for the plant's stress response. Additionally, the light environment affects the plant's responses to biotic intruders such as pathogens or insect herbivores. Light influence many stress responses resulting in positive growth-defense trade-offs. Under shade, however, plants prioritize growth over defense and stress responses. In this review, we summarize the impact of light as a stressor and its influences on abiotic and biotic stress responses with special focus on the role of the different light receptors and the crosstalk between light signaling components and stress response pathways.
\end{abstract}

\section{ACKNOWLEDGEMENTS}

We acknowledge funding by Deutsche Forschungsgemeinschaft (DFG) through Collaborative Research Centre 973 (www.sfb.973) and project Schm 814/29-1. There are no conflicts of interests.

\section{INTRODUCTION}

Continuously changing environmental conditions challenge plants endlessly. Sunlight is one of these environmental factors which not only provides plants with energy for photosynthesis but also delivers information about the time of the day and the season. Plants are constantly exposed to changes in light intensity and quality due to weather conditions (e.g. sunny or cloudy skies) but also due to the sun's inclination which changes over the year as a result of seasonal shifts. For plants under canopies, these seasonal shifts are extremely challenging. Spring is accompanied by canopy closure and consequently, light quantity reduces. More particular, the red:far-red (R:FR) ratio and total amount of blue light reaching understory plants are strongly reduced (Casal, 2013). Therefore, perception of light quality and quantity and adequate responses are essential for the plant's survival in these changing, and often adverse, light environments.

Different parts of the solar light spectrum are sensed by specific photoreceptors (for review, see Paik and Huq, 2019). InArabidopsis thaliana, R/FR light is perceived by phytochromes (phyA to phyE), blue light by cryptochromes (CRY1, CRY2 and CRY3), phototropins (PHOT1, PHOT2), and F-box containing flavinbinding proteins (ZEITLUPE, FKF1/LKP2), and UV-B light by the UVR8 receptor.

Phytochromes predominantly absorb red/far-red light. Their photosensory activity is the result of a lightinduced, reversible switching between the inactive Pr and the active Pfr form in response to far-red and 
red light, respectively. In A. thaliana, five phytochromes have been identified (phyA to phyE). Most plant responses are attributed to phyA and phyB. Photo-activated phytochromes repress the activity of SUPPRESSOR OF PHYA1/CONSTITUTIVE PHOTOMORPHOGENIC1 (SPA1/COP1), an E3 ubiquitin ligase. SPA1/COP1 degrades the ELONGATED HYPOCOTYL5 (HY5) transcription factor essential for the light-dependent transcriptional regulation of plant responses to light (Liu et al., 2015; Shin et al., 2013). Active phytochromes mediate the degradation of PHYTOCHROME INTERACTING FACTORS (PIFs) which repress photomorphogenesis ( $\mathrm{Li}, \mathrm{Li}$, Wang, \& Deng, 2011). Besides their essential role in shade avoidance, phytochromes are also involved in regulation of seed germination, photomorphogenesis, flowering time, the circadian clock and gravitropism (Casal, 2013; Correll et al., 2003; Franklin \& Whitelam, 2007b; Lin, 2000; Nagy \& Schafer, 2002; Pierik \& de Wit, 2014; Somers, Devlin, \& Kay, 1998).

Blue/UV-A light is perceived by cryptochromes which contain a flavin adenine dinucleotide (FAD) as chromophore (Banerjee et al., 2007; Malhotra, Kim, Batschauer, Dawut, \& Sancar, 1995; Wang \& Lin, 2020). The cryptochromes are activated through interconversion of flavin redox states (Bouly et al., 2007) caused by photoexcitation (Liu, Liu, Zhao, Pepper, \& Lin, 2011). As a consequence of the photocycle of the FAD in cryptochromes, small amounts of reactive oxygen species (ROS) can be produced in the nucleus (ElEsawi et al., 2017). CRY1 and CRY2 mediate several blue light-regulated responses such as the inhibition of hypocotyl elongation (Ahmad \& Cashmore, 1993), root growth (Canamero et al., 2006), the regulation of the circadian clock (e.g. Devlin and Kay, 2000; Somers et al., 1998), flowering time (Guo, Yang, Mockler, \& Lin, 1998), and stomatal development (Kang, Lian, Wang, Huang, \& Yang, 2009). Two different ways of CRY-mediated signal transduction have been discovered (reviewed in Wang and Lin, 2020): the cryptochrome-interacting basic helix-loop-helix1 (CIB1)-dependent CRY2 regulation of transcription (Liu et al., 2008) and the (SPA1/COP1)-dependent proteolysis (Liang et al., 2018). Both pathways depend on direct interaction between CRYs and their signaling components to modulate gene expression or protein stability in response to blue light (Liu et al., 2011).

Phototropins also absorb blue light and are involved in the regulation of light-dependent processes that serve to optimize photosynthesis (Gallagher, Short, Ray, Pratt, \& Briggs, 1988). They are members of an AGC kinase family (cAMP-dependent protein kinase A, cGMP-dependent protein kinase G and phospholipiddependent protein kinase C), with two photosensory LOV domains (LIGHT OXYGEN VOLTAGE) (Bögre, Okresz, Henriques, \& Anthony, 2003; Christie, Salomon, Nozue, Wada, \& Briggs, 1999; Taylor \& Zhulin, 1999). The LOV domains bind the cofactor flavin mononucleotide (FMN) and function as a blue light sensor that is autophosphorylated upon blue light photoexcitation. This activates the C-terminal kinase domain, regulating in turn other proteins. PHOT1 and PHOT2 have partially overlapping functions such as phototropism, stomatal opening, chloroplast accumulation, and cotyledon and leaf expansion. In addition, PHOT1 is involved in regulating hypocotyl elongation and PHOT2 mediates chloroplast avoidance movement (Christie, 2007).

The ZEITLUPE (ZTL) family belongs to the LOV domain photoreceptors. This family includes ZTL, FLAVIN-BINDING KELCH REPEAT F-BOX1 (FKF1) and LOV KELCH PROTEIN2 (LKP2; Ito, Song, \& Imaizumi, 2012; Ito et al., 2012; Takase et al., 2011). They have overlapping roles in controlling stability of circadian clock components and are involved in photoperiod control of flowering (Christie, Blackwood, Petersen, \& Sullivan, 2015; Kiba, Henriques, Sakakibara, \& Chua, 2007; Mas, Kim, Somers, \& Kay, 2003; Somers, Schultz, Milnamow, \& Kay, 2000; Song et al., 2014).

The photoreceptor UV RESISTANCE LOCUS8 (UVR8) has been identified in a screen for mutants defective in UV-B responses (Kliebenstein, Lim, Landry, \& Last, 2002; Rizzini et al., 2011). UVR8 exists as a dimer and upon UV-B absorption, active UVR8 monomers are formed which interact with COP1 thus preventing the degradation of HY5 (Yi \& Deng, 2005). The association of UVR8 and COP1 is disrupted by REPRESSOR OF UV-B PHOTOMORPHOGENESIS1 (RUP1) and RUP2 which induce re-dimerization (Heijde \& Ulm, 2013) thereby preventing UVR8-signaling. In addition to the UVR8/COP1/HY5 pathway, UVR8 can also directly bind to transcription factors, repressing brassinosteroid promoted plant growth (Liang et al., 2018) and auxin-induced root branching (Yang et al., 2020). 
Light perception is essential for the regulation of developmental processes and to respond to various biotic and abiotic stresses. Chloroplasts and photoreceptors are vital hubs to perceive and transmit light information. The regulatory functions of the main light signaling components have been underestimated in stress research. More and more studies demonstrate that light might equip plants with warning signals to prepare themselves for adverse environmental conditions. Various instances of crosstalk between light signaling pathways and stress responses have been discovered. In this review, we will summarize the impact of light as a stressor and its influence on biotic and abiotic stress responses. We especially focus on how the light signaling pathways are interweaved with stress response pathways. However, it should be noted that there are also stress responses independent of light which are crucial for plant survival under adverse environmental conditions. A summary of the key findings concerning the impact of light on abiotic and biotic stress responses can be found in the information box.

\section{LIGHT AS A STRESSOR}

Too much light can be harmful for plants. Excess light (EL) causes oxidative stress resulting in photodamage and photoinhibition (Ganguly, Crisp, Eichten, \& Pogson, 2018). Recurrent periods of EL followed by lower light intensities (fluctuating light stress), result in strong stress responses. Also the prolongation of the light period causes stress (photoperiod stress; Nitschke et al., 2016). The ultraviolet (UV) part of light causes stress leading to serious damage of DNA (Hideg, Jansen, \& Strid, 2013). In the sections below, we describe the different mechanisms plants have evolved to cope with light stress with a special focus on the relevance of the light signaling pathways (Figure 1).

\section{Excess light stress}

When light intensity exceeds the energetic demand of photosynthesis, the exposure to excessive light (Figure 1A) causes damage to the photosynthetic machinery, especially to photosystem II (PSII), and thus causes photoinhibition. Protein D1, which is part of the reaction center of PSII, is one of the main targets of photoinhibition (Edelman \& Mattoo, 2008). The damaged D1 protein is removed and replaced by de novo synthesized proteins during the D1 repair cycle (Baena-Gonzalez \& Aro, 2002). This process is highly dependent on the membrane fluidity of the thylakoid membranes (Yamamoto, 2016). When the rate of photodamage exceeds the $\mathrm{D} 1$ repair capacity, photoinhibition takes place.

Plants have developed several mechanisms to avoid photodamage to PSII (Takahashi \& Badger, 2011). In response to direct sunlight, plants move their leaves (heliotropism) and chloroplasts group at cell walls parallel to the direction of the light to avoid absorption of excessive sunlight (chloroplast avoidance response). PHOT2, together with the CHLOROPLAST UNUSUAL POSITIONING1 (CHUP1) protein, are essential for the chloroplast avoidance response (Oikawa et al., 2003; Figure 1A). Screening against damaging radiation (UV and visible light) by phenolic compounds (Agati, Azzarello, Pollastri, \& Tattini, 2012) helps to avoid damage to PSII and subsequent D1 protein degradation (Takahashi \& Badger, 2011). When these avoidance mechanisms are insufficient, plants have to deal with the EL absorbed by the photosynthetic pigments. EL causes the generation of ROS (Apel \& Hirt, 2004) resulting in oxidative stress. ROS trigger a direct inhibition of the D1 repair cycle rather than causing damage to D1 (Takahashi \& Murata, 2008). To avoid oxidative stress, plants reduce ROS by several ROS scavenging enzymes and antioxidants (Mittler, Vanderauwera, Gollery, \& Van Breusegem, 2004). Plants can also dissipate EL absorbed by the light-harvesting complexes as heat in a process called thermal energy dissipation $(\mathrm{qE})$. $\mathrm{qE}$ is part of the non-photochemical quenching mechanisms (NPQ) in plants (Holt, Fleming, \& Niyogi, 2004) and can be activated by the generation of a $\mathrm{pH}$ gradient across the thylakoid membrane in which the cyclic electron transport chain is essential (Shikanai, 2007). In addition, the photorespiratory pathway maintains the energy utilization in the Calvin cycle resulting in a reduction of ROS generation.

EL stress (Figure 1A) results in specific and dynamic transcriptional changes in gene expression (Li, Gao, Ren, \& Tang, 2018). A recent study identified a core set of high light (HL)-responsive genes, independent of heat (Huang, Zhao, \& Chory, 2019). The analysis revealed that plants respond to HL through regulation of hormones, photosynthesis and the phenylpropanoid pathway and that both abscisic acid (ABA) 
and PIFs are required for the HL response (Huang et al., 2019). Moreover, it was shown that blue/UVA photoreceptors are responsive to HL. The involvement of CRY1, in a chloroplast-independent manner, was shown in an earlier study (Kleine, Kindgren, Benedict, Hendrickson, \& Strand, 2007). Genome-wide gene expression analysis revealed that among the HL-responsive genes 77 are CRY1-dependent, and 25 were ELONGATED HYPOCOTYL 5 (HY5)-dependent. Both cry1 and hy5 mutants showed a misregulation of EARLY LIGHT-INDUCIBLE PROTEIN1(ELIP1 ) and ELIP2 whose induction is mediated via CRY1 in a blue-light intensity-dependent manner (Kleine et al., 2007).

In response to EL, CRY1 is also involved in the accumulation of anthocyanins through the induction of PRODUCTION OF ANTHCYANIN1 /2 (PAP1 /PAP2 ; Kleine et al., 2007) in a COP1/SPA1/HY5dependent manner (Maier \& Hoecker, 2015). Growth of plants under blue/UV-A light prior to EL treatment revealed that CRYs ameliorate the response to HL stress by promoting the accumulation of soluble phenolic compounds in leaves and thus improving the photosynthetic efficiency (Brelsford et al., 2019). A similar role with respect to flavonoid accumulation was also shown for UV-A and the UVR8 receptor (Brelsford et al., 2019). Cryptochrome function during HL stress is connected to their direct interaction with the oxidative stress system. Danon, Coll, and Apel (2006) showed that the light-dependent release of singlet oxygen alone is not sufficient to induce programmed cell death in fluorescent ( $f(u)$ mutant seedlings but that it has to act together with a second concurrent blue light reaction. This blue light-dependent signal is caused by the activation of the cryptochrome photoreceptor itself. Especially, CRY1 activation is associated with ROS formation and is able to induce cell death in insect cells (Consentino et al., 2015; Jourdan et al., 2015). The FAD-domain of CRY1 is oxidized in the dark-adapted state of the receptor and becomes reduced upon illumination, forming a neutral radical flavin redox state which is linked to biological activity of the receptor. Following flavin reduction, flavin re-oxidation occurs in a light-independent reaction leading to the production of hydrogen peroxide $\left(\mathrm{H}_{2} \mathrm{O}_{2}\right)$ and other ROS which accumulate in the nucleus (El-Esawi et al., 2017).

\section{Stress caused by fluctuating light}

During the day, plants are exposed to fluctuations in the light environment (Figure 1B). Understory plants experience this fluctuating light (FL) just like plants grown in the fields which face FL due to cloud movement or changes in sun elevation. In constant high light, the PSII antenna systems switch from light absorption to heat dissipation, known as the NPQ, preventing photoinhibition (see 2.1). Under FL, however, chloroplasts are not able to rapidly switch on or off this heat dissipation system due to the slow NPQ relaxation (Kono \& Terashima, 2014).

FL causes PSI photoinhibition due to a limitation of the electron flow on the acceptor side of PSI and an accumulation of ROS (Sonoike, 1996) which damages the iron-sulfur centers of PSI (Sonoike \& Terashima, 1994). Since damaged PSI is not de novo repaired, PSI photoinhibition has to be avoided (Kudoh \& Sonoike, 2002). Therefore, plants developed short-term and long-term acclimation responses (for review, see Kono \& Terashima, 2014).

The short-term mechanisms include alternative electron transport flows (Figure 1B). Among the two known cyclic electron transport flows (CEFs) around PSI are the NADH-dehydrogenase-like complex-dependent pathway (NDH-mediated CEF; Shikanai, 2016) and the proton gradient regulation5 (PGR5)-mediated pathway (PGR-mediated CEF; Munekage et al., 2002). The PRG5-mediated CEF is essential for the protection of PSI by improving the PSI acceptor-side limitation (Kono, Noguchi, \& Terashima, 2014; Kono \& Terashima, 2014, 2016). Similarly, the pseudocyclic electron flow, also called water-water cycle (WWC) (Asada, 1999), or the Mehler ascorbate peroxidase (MAP) pathway (Schreiber, Hormann, Asada, \& Neubauer, 1995) are crucial in the response to FL (Kono et al., 2014). These alternative electron flows act as electron sinks thereby protecting plants from photoinhibition. Far-red light increased the photoprotection of PSI against FL (Kono, Yamori, Suzuki, \& Terashima, 2017). This might be due to the beneficial effects of FR light on photosynthesis thereby accelerating NPQ relaxation and PSII yield (Kono et al., 2017). In a recent study, a FLUCTUATING-LIGHT-ACCLIMATION PROTEIN1 (FLAP1) was identified probably controlling NPQ formation during FL (Sato et al., 2017). 
Long-term adjustments in response to FL have rarely been studied. A recent genome-wide transcriptome profile analysis in Arabidopsisrevealed that a global reprogramming of gene expression to FL occurs (Schneider et al., 2019). Especially genes related to photoprotection, photosynthesis, photorespiration, pigments, prenylquinone and vitamin metabolism are differently expressed. Moreover, they also revealed that FL acclimation interacts with leaf developmental stage and the time of the day pointing to a possible role for the circadian clock. In addition, the authors hypothesized that blue light might positively affect FL acclimation (Schneider et al., 2019).

\section{Photoperiod stress}

Changes of the photoperiod, in particular a prolongation of the light period, induces photoperiod stress (originally circadian stress; Nitschke et al., 2016; Nitschke, Cortleven, and Schmülling, 2017; Figure 1C). Amongst others the stress phenotype is characterized by the induction of stress marker genes such as ZAT12 and $B A P 1$ and increased oxidative stress during the night following an extended light period. The next day, a significant reduction of PSII maximum quantum efficiency $(\mathrm{Fv} / \mathrm{Fm})$ and eventually programmed cell death in the leaves ensues. Photoperiod stress induces an oxidative burst-like response and is associated with increased apoplastic peroxidase and decreased catalase activities (Abuelsoud, Cortleven, \& Schmülling, 2020). Arabidopsis mutants with a reduced cytokinin content or signaling are more sensitive to the stress than wild-type plants indicating a protective function of the hormone. Genetic studies revealed that especially root-derived trans -zeatin protects from photoperiod stress acting through the ARABIDOPSIS HISTIDINE KINASE 3 (AHK3) receptor and the transcriptional regulators ARABIDOPSIS RESPONSE REGULATORS ARR2, ARR10 and ARR12 (Frank, Cortleven, Novak, \& Schmülling, 2020; Nitschke et al., 2016). Also certain mutants of the circadian clock showed a strong stress response, which have in common a lowered expression or impaired function of CIRCADIAN CLOCK ASSOCIATED1 (CCA1) or LATE ELONGATED HYPOCOTYL (LHY) (Nitschke et al., 2016), representing two key regulators of the circadian clock. This indicates that a functional clock is also essential to cope with photoperiod stress. Recurrent photoperiod stress events reduce the stress response to subsequent stresses (personal communication).

Which part of the light signaling pathway or which light quality has an impact on the strength of the photoperiod stress response is as yet not known. Similarly, the natural conditions under which photoperiod stress occurs is presently being explored.

\section{UV stress}

Ultraviolet (UV) light is part of the solar spectrum and can be divided into three wavebands: UV-C (200 $280 \mathrm{~nm})$, UV-B $(280-315 \mathrm{~nm})$ and UV-A $(315-400 \mathrm{~nm})$. While low dose UV-B radiation is known to cause 'eustress', extreme irradiance can result in programmed cell death and so causes 'distress' (Hideg et al., 2013; Figure 1D). UV light is especially harmful to PSII (Ohnishi et al., 2005; Takahashi et al., 2010) but also causes photodamage to DNA, production of ROS and a change in cellular processes like photomorphogenic or wound responses (Muller-Xing, Xing, \& Goodrich, 2014).

DNA damage by UV includes double strand breaks and the formation of covalent bonds between adjacent pyrimidines, the so-called cyclobutene pyrimidine dimers (CPDs) which result in inhibition of transcription and replication (Britt, 2002). Light-dependent CPD photolyases repair these dimers restoring the native DNA form (Britt, 2002). The expression of CPD photolyase genes (PHR ) is controlled by UV-A in a phyA-dependent, by UV-B in a UVR8-dependent, and by blue light in a CRY-dependent manner (Li et al., 2015). The UVR8-COP1-HY5 pathway is the main signaling cascade involved in UV tolerance. CRYs and UVR8 interact to regulate plant growth under UV light (Rai et al., 2019). Recently, it was shown that cryptochromes, especially via CRY1, can modulate the UVR8 photoreceptor activity contributing to increased UV tolerance (Tissot \& Ulm, 2020).

To cope with UV damage, plants accumulate UV-protective compounds such as phenolics in the vacuoles of the leaf epidermis (Emiliani, Grotewold, Falcone Ferreyra, \& Casati, 2013; Hectors et al., 2014; Takahashi et al., 2010). Among them are phenolic acids, anthocyanins and flavonols. The flavonoid biosynthesis pathway is regulated by the PRODUCTION of FLAVONOL GLYCOSIDES (PFG) family of transcription factors 
which are induced by UV-B in an UVR8- and HY5-dependent manner (Brown \& Jenkins, 2008; Davey et al., 2012). Among the key genes encoding biosynthetic enzymes of flavonoid biosynthesis especially CHALCONE SYNTHASE(CHS), CHALCONE ISOMERASE (CHI) and FLAVONOL SYNTHASES (FLS ) transcript levels are strongly regulated by UV light in an UVR8-dependent manner (Brown \& Jenkins, 2008; Favory et al., 2009). Furthermore, UV irradiance triggers the expression of genes involved in protection against oxidative stress and photo-oxidative damages to reduce the ROS produced during UV stress. Similarly, transcription factors and proteases which play a key role in UV tolerance are induced by UV (Brown et al., 2005; Muller-Xing et al., 2014; Figure 1D).

\section{LIGHT AND TEMPERATURE STRESS}

Abrupt drops or boosts of temperature impose dramatic effects on plant survival. As sessile organisms, plants are subjected to strong fluctuations in temperature during the day. The lowest temperature often coincides with the night while midday is often the warmest moment of the day. It is therefore not unexpected that temperature responses are closely linked with light signals. Light signals not only reset the circadian clock but also provide plants with information concerning e.g. seasonal changes or day length which enables them to anticipate future temperature conditions (Figures 2 and 3 ).

\section{Light and cold acclimation}

Low temperatures slow down metabolic processes in plants and adversely affect growth (Figure 2). Some plants are able to increase their tolerance after exposure to low non-freezing temperatures, a process called cold acclimation (Guy, Kaplan, Kopka, Selbig, \& Hincha, 2008; Levitt, 1980; Thomashow, 1999). The changes occurring in response to low temperatures resulting in increased freezing tolerance include transcriptional and posttranscriptional changes that can be ABA -dependent or -independent. The best understood cold regulatory pathway in Arabidopsis is the C-repeat/dehydration-responsive element binding factor (CBF/DREB) signaling cascade. The CBF regulon consists of the stimulation of the central regulatory genes, $C B F 1$ to $C B F 3$ , after cold temperatures resulting in the induction of cold-regulated (COR) genes (Pareek, Khurana, Sharma, \& Kumar, 2017; Thomashow, 2010). The induction of CBF genes is under control of CCA1 and LHY , the central regulators of the circadian clock, with a peak around ZT4-8 (zeitgeber) and a trough at ZT16 (Fowler, Cook, \& Thomashow, 2005; Dong, Farre, \& Thomashow, 2011. A direct interaction between the clock and the cold responses forms PIF7whose activity is regulated by TOC1 (TIMING OF CAB EXPRESSION 1 ) together with phyB to act as a transcriptional repressor of CBF2 (Kidokoro et al., 2009). Besides this circadian regulation of cold acclimation, light and photoperiod are also crucial.

Light is required for the induction of several genes involved in cold acclimation, including the CBFs (H. J. Kim, Kim, Park, \& Kim, 2002; Soitamo, Piippo, Allahverdiyeva, Battchikova, \& Aro, 2008) (Figure 2). Light signaling mediated through phyB plays an important role in cold-induced gene expression not only in Arabidopsis (Kim et al., 2002) but also in rice (He et al., 2016) and tomato (Wang et al., 2016). Recently, it was shown that phyB acts downstream of CBFs to positively regulate freezing tolerance by direct interaction with CBFs (Jiang et al., 2020) which additionaly interact with PIF3 (Jiang et al., 2017). The CBF-PIF3phyB interaction prevents PIF3 and phyB from undergoing light-dependent degradation. The cold-stabilized phyB promotes the degradation of PIF1, PIF4 and PIF5 resulting in the expression of the COR genes, thus increasing freezing tolerance in Arabidopsis (Jiang et al., 2020). In tomato, it was reported that phyA and phyB function antagonistically to regulate cold acclimation. Far-red light-induced activation of phyA leads to the induction of $\mathrm{ABA}$ signaling and subsequent JA signaling causing an activation of the CBF pathway resulting in cold acclimation (Wang et al., 2016). A similar influence of light quality was shown inArabidopsis . A low red to far-red ratio (R:FR) light signal increases $C B F$ gene expression in a circadianregulated but $\mathrm{ABA}$-independent manner. This light quality-dependent increase in $C B F$ expression enables plants to confer freezing tolerance at higher temperatures than those required for cold acclimation (Franklin \& Whitelam, 2007a). In view of a reduced ambient temperature, shorter days and increased twilight (during which the R:FR ratio is lower) during autumn, this regulatory mechanism might initiate a certain degree of cold acclimation before the onset of winter (Franklin \& Whitelam, 2007a). A comparable effect of a reduced R:FR ratio on frost tolerance is also found in barley (Ahres, Gierczik, Boldizsár, Vítámvás, \& Galiba, 2020). 
Also, the photoperiod can regulate the $C B F$ regulon (Figure 2). Lee and Thomashow (2012) showed that SD-grown plants are more freezing tolerant than long day (LD)-grown plants. Under LD conditions, the $C B F$ regulon is repressed by phyB, PIF4 and PIF7 causing a downregulation of freezing tolerance. This repression is relieved by shortening of the day length causing an increased expression of the $C B F$ genes preparing plants for upcoming colder temperatures. In addition, geographical distant accessions of Arabidopsis exhibit a difference in freezing tolerance which can be related to the photoperiod conditions they are geographically associated to (Alonso-Blanco et al., 2005).

Another key regulator of cold and light is HY5, a bZIP transcription factor which has a prominent role in light signaling (Lau \& Deng, 2010; Figure 2). In response to low temperatures, HY5 is responsible for the induction of ca. $10 \%$ of all cold-inducible genes in Arabidopsisthrough the Z-box containing a lowtemperature-responsive element (LTRE). Among the HY5-inducible genes are those involved in anthocyanin biosynthesis which protect plants from high ROS accumulation (Harvaux \& Kloppstech, 2001). HY5 levels are also transcriptionally regulated by low temperature via a CBF- and ABA-independent pathway and posttranslationally via nuclear exclusion of COP1.

Together, these studies clearly point to a complex crosstalk between light and temperature. Light provides information concerning daily or seasonal changes to plants - be it light quality or quantity - enabling them to get prepared for colder temperatures by adapting the cold acclimation response but also by reducing ROS (Figure 2).

\section{Light and thermotolerance}

Plants cope with normally lethal high temperatures after being exposed to lower non-lethal high temperatures in a process called thermotolerance (Larkindale, Hall, Knight, \& Vierling, 2005; Larkindale \& Vierling, 2008; Song, Jiang, Zhao, \& Hou, 2012). High temperatures damage cellular components resulting from heat-induced oxidative stress (Larkindale \& Knight, 2002; Pospisil, 2016), affect membrane fluidity and permeability (Sangwan, Orvar, Beyerly, Hirt, \& Dhindsa, 2002), alter enzyme activity resulting in metabolic imbalances (Kampinga, Brunsting, Stege, Burgman, \& Konings, 1995) and negatively influence photosynthesis by impairing PSII electron transport and the D1 repair cycle (Balfagon et al., 2019; Murata, Takahashi, Nishiyama, \& Allakhverdiev, 2007; Pospisil, 2016). A key process during thermotolerance is the induction of heat shock factors (HSFs) activating the expression of protective chaperones, such as HEAT SHOCK PROTEIN 70 (HSP70), preventing protein denaturation (Mittler, Finka, \& Goloubinoff, 2012).

In Arabidopsis, thermotolerance varies diurnally reaching a peak at noon and a trough at dawn (Han, Park, \& Park, 2019a). This regulation is correlated with the higher expression of HSP s during the light period (Dickinson et al., 2018). Light gates the magnitude of the response to high temperature, with the expression of HSPs being much higher after a temperature shift. This light priming effect on thermotolerance is caused by light-induced chloroplast-to-nucleus signaling components such as ROS or the redox state of the plastoquinone (PQ) pool (Figure 3). A similar light priming effect, independent of the above mentioned one, was also observed by Han et al. (2019a). They found that light primes the HEAT SHOCK FACTOR A1 (HSFA1)-mediated thermal induction of ASCORBATE PEROXIDASE2(APX2) gene expression under high temperatures in a phyB-dependent, but PIF-independent manner, resulting in ROS detoxification necessary for the induction of thermotolerance (Han et al., 2019ab; Han, Park, \& Park, 2019ab). phyB also acts as a molecular switch to turn on or off several heat stress response genes under different light conditions resulting in thermotolerance (Song, $\mathrm{Liu}, \mathrm{Hu}, \& \mathrm{Wu}, 2017$ ). These studies point to a key role of phyB in thermotolerance. Indeed, phyB was found to function as thermosensor: the far-red light-activated reversion of Pfr is accelerated at warm temperatures (Jung et al., 2016; Legris et al., 2016). As a consequence, the inhibitory function of phyB on PIF4 which is an important component of the plant high temperature signaling (Koini et al., 2009) is lost, resulting in a stabilization of PIF4 (Jung et al., 2016). This causes the induction of auxin-responsive genes such as IAA19 resulting in morphological changes including leaf hyponasty and petiole elongation contributing to thermotolerance (Jung et al., 2016; Koini et al., 2009). Not only heat itself diminishes the activity of phyB by increasing the thermal reversion, but also low red/far-red ratios typical of shade reduce the activity of phyB, thereby increasing the abundance of PIFs resulting in a higher tolerance to heat (Arico 
et al., 2019). Low red to far-red ratio decreases the transcript levels of fatty acid desaturase (FAD ) resulting in a shift in fatty acid composition towards more saturated fatty acids. During heat stress, the produced ROS promote peroxidation of unsaturated fatty acids (Anjum, Khan, Sofo, Baier, \& Kizek, 2016). By reducing the targets of oxidative damage, thermotolerance increases (Arico et al., 2019).

As already mentioned before, PIFs and especially PIF4, are key transcriptional regulators integrating multiple environmental cues thereby promoting plant responses to elevated temperatures (Figure 3). CRY1 represses high temperature-induced hypocotyl elongation through direct physical interaction with PIF4 thereby reducing its transcription (Ma et al., 2016). Independent of the phyB-PIF4 regulon, blue light perceived by phototropins activates $\mathrm{H}^{+}$-ATPases and 14-3-3 proteins which results in stomatal opening causing leaf cooling and so improves thermotolerance (Kostaki et al., 2020). UV-B perceived by the UVR8 photoreceptor also represses plant responses to higher temperatures by inhibiting PIF4 via a COP1-dependent manner involving HFR1 (Hayes et al., 2017; Yin, 2017). PIF4 is also transcriptionally and posttranscriptionally regulated by ELF3 via two separate pathways. In light, phyB promotes ELF3 accumulation which binds to PIF4 in an evening complex (EC)-independent manner thus reducing PIF4 activity (Nieto, Lopez-Salmeron, Daviere, \& Prat, 2015). Under high temperatures, BBX18 and BBX23 interact with ELF3 and negatively control ELF3 protein accumulation resulting in a release of the ELF3-mediated repression of PIF4 causing a thermotolerance response (Ding et al., 2018). Together with ELF4 and LUX, ELF3 forms an EC-repressive complex that binds to thePIF 4 promotor early during the night (Nieto et al., 2015). This action of the EC is temperature dependent, with a weaker binding of the complex at higher temperatures, suggesting that the EC might also act as a thermosensor (Ezer et al., 2017). Recently, it was found that ELF4 is a key modulator of the thermosensitive EC activity (Silva et al., 2020). An overview of cross-talk between light and thermotolerance is given in Figure 3.

\section{LIGHT AND DROUGHT STRESS}

Drought resistance is an important trait to overcome detrimental effects on plant performance and productivity. Drought activates specific signaling pathways resulting in physiological and developmental adaptations to optimize water use and respond adequately to drought stress (Fahad et al., 2017; Nakashima, YamaguchiShinozaki, \& Shinozaki, 2014). Although the plant hormone ABA is essential for the response to drought stress, both ABA-dependent and ABA-independent signaling cascades are involved in the transcriptional regulation of target genes to increase the plant's resistance to drought stress (Joshi et al., 2016; Kim et al., 2012; Mahmood et al., 2019).

One of the first responses upon a drought signal is the closure of plant stomata to reduce water loss via transpiration. ABA biosynthesis is promoted by water loss (Outlaw, 2003) and stomatal closure under drought stress is activated by the perception of ABA (Daszkowska-Golec \& Szarejko, 2013). Besides ABA, stomatal opening is also diurnally regulated and influenced by temperature (Tallman, 2004) and light (Matthews, Vialet-Chabrand, \& Lawson, 2020). Stomatal aperture is driven by two distinct pathways: the "red" or photosynthetic response and the guard cell-specific "blue" response involving phototropins. CRY1 has been shown to work additively to the phototropins in a COP1-dependent way to regulate stomatal opening in response to blue light (Mao, Zhang, Sang, Li, \& Yang, 2005; Figure 4). In response to red light, phyB mediates stomatal opening in a COP1- or PIF3/PIF4-dependent way (Wang, Lian, Kang, \& Yang, 2010). Although the regulation of stomatal opening is essential for the drought stress response and is strongly influenced by light, only few studies have described a role connecting light and light signaling components to drought tolerance. While Arabidopsis cry1 cry2 mutants are less drought-tolerant than wildtype, CRY1 overexpressor plants show excessive water loss which is associated with the repressor function of COP1 on stomatal opening (Mao et al., 2005). Gonzalez, Ibarra, Piccoli, Botto and Boccalandro (2012) revealed that ArabidopsisphyB mutants wilt earlier than wildtype due to the maintenance of open stomata and that transcription levels of ABA-induced genes are strongly reduced in phyB mutants after ABA treatment. Thus, it was concluded that phyB increases drought tolerance in $A$. thaliana by enhancing ABA sensitivity. Previously, it was already shown that phyB increases stomatal density, the stomatal index and influences the presence of stomata on both sides of the leaf in high R:FR ratios (Boccalandro et al., 2009). This would imply that under these 
conditions, plants have a higher water use, however, in response to drought, stomata are quickly closed through an increased ABA sensitivity (Gonzalez et al., 2012).

The response to drought stress can be influenced by the light quality (Figure 4), in particular by shade conditions. Seedling survival of Ghanaian trees is higher in shade than in high light suggesting that shade enhances plant performance under drought stress conditions (Amissah, Mohren, Kyereh, \& Poorter, 2015). The activity of osmoprotectants and antioxidants was also increased under shade conditions suggesting that pretreatment with shade might help to overcome the drastic effects of drought in soybeans in dense cropping systems (Asghar et al., 2020). An overview of the interactions of light with other pathways resulting in drought tolerance can be found in Figure 4.

\section{LIGHT AND BIOTIC STRESS}

Plants are also exposed to several biotic environmental factors such as pathogens or herbivores, affecting their performance. The responses to these biotic stresses are influenced by light (Ballaré, 2014). In particular shade conditions have a strong influence on plant responses to pathogen and herbivore attacks (Ballaré, 2014; Fernandez-Milmanda et al., 2020). In the following sections, we will discuss in more detail the role of light in plant responses to pathogen and herbivore attack, and to neighboring plants. An overview of the mechanisms involved can be found in Figure 5.

\section{Light and pathogen attack}

Plants possess a multi-layered immune system which enables them to recognize pathogen attacks and subsequently initiate defense responses (reviewed in De Wit, 2007). After breaking through the plant's cell wall, pathogens are confronted with active plant immunity, consisting of the primary innate immunity and a host-specific, secondary innate immune response (for review, see Chisholm, Coaker, Day, and Staskawicz, 2006; Delprato, Krapp, and Carrillo, 2015; Jones and Dangl, 2006). During the primary innate immune response, pathogen-associated molecular patterns (PAMPs) are detected by pattern recognition receptors (PRRs) resulting in PAMP-triggered immunity (PTI). PTI includes the activation of several defense responses such as induction of pathogen-responsive $(P R)$ gene expression, ROS production, or alterations in hormone signaling pathways involving salicylic acid (SA) and jasmonic acid (JA). In order to inhibit innate plant immunity, certain pathogens produce effector proteins that are encoded by avirulence (avr) genes (De Wit, 1997, 2007; Shamrai, 2014). The secondary immune response enables plants to recognize and counteract the pathogen-derived effectors through resistance $(\mathrm{R})$ proteins encoded by $R$ genes (De Wit, 2007) which results in effector-triggered immunity (ETI) in the affected plants (Jones \& Dangl, 2006). PTI and ETI trigger the same plant responses and have also similar signaling pathways but these are differently used (for review, see Tsuda and Katagiri, 2010). During ETI, programmed cell death is considered as a component of the hypersensitive response (HR) of plants (Chisholm et al., 2006) which is affected by intracellular ROS (Torres, 2010). ROS contribute to the establishment of systemic acquired resistance (SAR) that ensures defense in distant plant parts following ETI (Karpinski, Gabrys, Mateo, Karpinska, \& Mullineaux, 2003; Zhang et al., 2018).

Light is crucial for activating full resistance responses in plant-pathogen interactions (Ballaré, 2014; Delprato et al., 2015; Roberts \& Paul, 2006; Roden \& Ingle, 2009; Trotta, Rahikainen, Konert, Finazzi, \& Kangasjarvi, 2014). Already in 1970, researchers showed that HR is dependent on light (Lozano and Sequira, 1970). For instance, in contrast to dark, light affects local defense responses such as the accumulation of SA, SA glucoside (SAG), but also SA-responsive pathogenesis-related protein 1 (PR1) and light can induce key genes of the phenylpropanoid pathway in A. thaliana after inoculation with an avirulent Pseudomonas syringae pv.maculicola bacterium (Psm ES4326 containing the avirulence gene avrRpm1 ; Zeier, Pink, Mueller, \& Berger, 2004). Moreover, SAR development in response to the avirulent bacteria was completely lost when the primary infection process occurred in the absence of light. Not only SA biosynthesis, but also SA perception is influenced by light which is dependent on phyA and phyB (Genoud, Buchala, Chua, \& Metraux, 2002). In addition, Chandra-Shekara et al. (2006) demonstrated that exposure to prolonged darkness prior to inoculation with the Turnip Crinkle Virus (TCV) compromised the development of the HR and that the 
virus can spread systemically. The absence of light, however, did not influence the TCV-induced elevation of the SA levels resulting in SAR signaling to enhance resistance to future pathogen attacks and an HR (Conrath, 2006). These results indicate that light or a light-derived signal is required together with the SA-dependent pathway to positively modulate the early resistance to TCV.

Plant immune responses to pathogen attack are also affected by the length of the light period. In particular, SA and PR1 accumulation as well as the magnitude of the HR correlated with the length of the light period in A. thaliana plants ecotype Col-0 inoculated with the avirulent bacterium Psm ES4326 avrRpm1 (Griebel \& Zeier, 2008). The plant circadian clock does not seem to be responsible for this enhanced defense after longer exposure to light before bacterial infection (Griebel \& Zeier, 2008), though the possible involvement of circadian-regulated stomata in the defense was not considered by the inoculation method (Roden \& Ingle, 2009). A comparable effect was also described in Arabidopsis plants ecotype Ler -0 infected with Cauliflower Mosaic Virus, as disease symptoms were stronger in SD-grown plants than in plants grown under LD conditions, although the virus replication was even higher in LD-grown Arabidopsis (Cecchini et al., 2002). On the transcriptional level, the interaction of the Arabidopsis hexameric promoter element FORC ${ }^{A}$ with its targets is influenced by the length of the light period (Evrard et al., 2009). ArabidopsisFORC ${ }^{\mathrm{A}}$ is especially conserved in the promoters of genes regulated by both pathogens and light, thereby connecting light signaling and pathogen resistance (Evrard et al. , 2009; Roden and Ingle, 2009).

Also, the light intensity also affects plant pathogen resistance (Roden and Ingle, 2009). Arabidopsis plants are less susceptible to infection with the virulent Pseudomonas syringae pv. DC3000 bacteria, when plants were subjected to high light in advance (Muhlenbock et al., 2008). This improved resistance in acclimated plants was observed in both, leaves treated with excess light and distant ones, indicating that excess excitation energy promotes local resistance and SAR to virulent pathogens in Arabidopsis (Muhlenbock et al. , 2008). The authors also showed that excess excitation energy stimulates several genes necessary for resistance to pathogens in addition to their importance in light acclimation (Muhlenbock et al., 2008).

During biotic stress defense, light signals are mediated through photoreceptors or chloroplasts (Ballare, 2014; Delprato et al., 2015; Roden \& Ingle, 2009). Especially plant phytochromes and red light have been connected to light-dependent defense responses. Nightly red light treatment significantly enhanced the resistance of tomato plants againstPseudomonas syringae pv. tomato (Pst) DC3000. This effect correlated with increased SA accumulation and defense-related gene transcription indicating that SA-mediated signaling pathways are involved in red light-induced resistance to pathogens (Yang et al., 2015). Two homologous transcription factors essential for phyA signaling, FAR-RED ELONGATED HYPOCOTYL 3 (FHY3) and FAR-RED IMPAIRED RESPONSE 1 (FAR1), negatively regulate SA signaling and plant immunity by regulating HEMB1 expression essential for chlorophyll biosynthesis (Wang et al., 2016). Arabidopsis phyA andphyB mutants are more susceptible to Pst DC3000avrRpt2 in light which might be connected to a reduced SA perception causing a decreased expression of PR1 (Genoud et al., 2002). In contrast, the pathogen resistance in TCV-infectedArabidopsis Dijon-17 plants is independent of phyA or phyB (Chandra-Shekara et al., 2006). Similarly, Griebel and Zeier (2008) suggested that the HR in Arabidopsis phyA and phyB mutants following Psm ES4326 avrRpm1 inoculation was similar to the response observed in wild-type Arabidopsis plants suggesting no functional role for phytochromes in plant ETI. However, functional phytochromes are necessary for SAR, as phyA phyB double mutants did not improve their resistance in systemic leaves following a first infection with virulent Psm ES4326 bacteria (Griebel \& Zeier, 2008). Together these studies indicate that phytochromes mediate plant resistance to pathogen attack which might be dependent on the specific plant response to the pathogen and dependent on the pathogen itself. Although several studies suggested that SAR is independent of cryptochromes or phototropins (Delprato et al., 2015; Griebel \& Zeier, 2008), Wu and Yang (2010) showed that CRY1 enhances plant resistance in response to Pst DC3000 avrRpt2 in both local and systemic leaves. They also revealed that CRY1 promotes PR1 gene expression in Arabidopsis , as PR1 expression decreased in cry1 mutants under continuous light (CL) following SA treatment, while an increase was observed in $C R Y 1$-overexpressing plants under the same conditions. Although the HR occurs independently of CRY1, the authors concluded that CRY1 positively regulates $\mathrm{R}$ protein-mediated resistance to Pst DC3000 in incompatible plant-pathogen interactions. Also, CRY2 and PHOT2 are, via a 
COP1-dependent signaling pathway, required for the stability of an $\mathrm{R}$ protein-providing resistance to TCV (Jeong, Chandra-Shekara, et al., 2010a; Jeong, Kachroo, \& Kachroo, 2010b). Besides blue and red light, also UV-B enhances plant resistance to pathogen attacks. It activates SA-associated defense mechanisms in a JA-deficient Arabidopsis mutant (Escobar Bravo et al., 2019) and enhances sinapate production in an UVR8-dependent manner upon infection with the fungus Botrytis cinerea (Demkura \& Ballare, 2012).

Not only photoreceptors are crucial for pathogen defense responses, but also chloroplasts are, as reviewed by Kangasjarvi, Neukermans, Li, Aro, and Noctor (2012), Trotta et al. (2014) and Delprato et al. (2015). Genoud et al. (2002) showed that functional chloroplasts are important for HR formation during incompatible plant-pathogen interactions. However, the expression of $P R$ genes does not require active chloroplasts and SA-induced defense responses do not rely on chloroplast-mediated production of carbohydrates. Chloroplastdependent biosynthetic pathways provide plants with defensive metabolites (Trotta et al. , 2014). The chloroplast redox status, in particular alterations in the redox status of the plastoquinone (PQ) pool, impacts both, acclimation to excess light as well as pathogen resistance (Muhlenbock et al. , 2008; Roden and Ingle, 2009). The calcium-sensing receptor CAS which is located in chloroplast thylakoid membranes and mediates stromal calcium signals is required for PTI as well as $R$ gene-regulated ETI. CAS not only controls SA accumulation but also mediates defense gene expression in response to PAMPs (Nomura et al., 2012). Chloroplasts themselves can also be target of pathogen-derived effector proteins (Kangasjarvi et al., 2012). For instance, the bacterial effector HopI1 secreted by Pseudomonas syringae pathogens remodels chloroplast thylakoid structures and inhibits SA increase (Jelenska et al., 2007). The cysteine protease HopN1 representing another effector of Pseudomonas bacteria inhibits ROS production in chloroplasts and negatively affects PSII activity (Rodriguez-Herva et al., 2012).

\subsection{Light and insect herbivory}

As insects feed, they damage the plants. Insect herbivores can be detected by the perception of damageassociated molecular patterns (DAMPs) or of herbivore-associated molecular patterns (HAMPs) which include fatty acid-amino conjugates (FACs; Heil, 2009). FACs are present in the oral secretion of most lepidopteran larvae (Yoshinaga et al., 2010). Although most of the molecular mechanisms connecting light with herbivore attack are not yet known, observations have been made indicating that especially UV-B light has a positive effect on the plant responses to insect herbivores (Escobar-Bravo, Klinkhamer, \& Leiss, 2017). For example, Caputo, Rutitzky and Ballare (2006) showed that UV-B influences the attractiveness of Arabidopsis plants to diamondback moths (Plutella xylstella ). Moreover, they described that this beneficial effect of UV-B light on the reduction of egg number was compromised in the jar1 mutant suggesting that intact JA biosynthetic and signaling pathway are required for the defense response. A similar beneficial effect of UV was also observed in thedefenseless1 tomato mutant which is deficient in JA. Here, a strong activation of SA-associated defense responses by UV after thrips infestation was observed (Escobar-Bravo et al., 2019). UV-B treatment also enhanced the resistance of Arabidopsis to Spodopera litura herbivores through a JA-dependent mechanism (Qi et al., 2018). In addition Radhika et al. (2010) demonstrated that in lima bean (Phaseolus lunatus) the JA-regulated secretion of extrafloral nectar (EFN) attracting ants which protect plants against herbivores is dependent on light (Kazan and Manners, 2011). These examples indicate that a close connection between herbivore resistance and UV-B signaling acting through JA biosynthesis and signaling pathways exists.

\subsection{Shade and biotic stress responses}

Under shade conditions, plant defense against pathogens and insects is weakened (Ballare, 2014; FernandezMilmanda et al., 2020). For instance,phyB Arabidopsis mutants are more susceptible to the fungal pathogen Fusarium oxysporum than wild-type plants (Kazan \& Manners, 2011). Similarly, tomato plants mutated in phyB are less resistant to Spodoptera eridania caterpillars or the thrips Caliothrips phaseoli (Izaguirre, Mazza, Biondini, Baldwin, \& Ballare, 2006). Also, Arabidopsis resistance to Botrytis cinerea and Pseudomonas syringae decreased after exposure to low R:FR ratios mimicking shade conditions (Cerrudo et al., 2012; de Wit et al., 2013). 
Low ratios of R:FR $(<1)$ are characteristic for shade and environments with densely standing plants resulting in a partial inactivation of PfrB. In plants, low R:FR ratios are usually associated with the shade avoidance syndrome (SAS). Common phenotypical changes related to SAS are leaf hyponasty, an increase in hypocotyl and internode elongation and extended petioles to gain as much light as possible (Sessa, Carabelli, Possenti, Morelli, \& Ruberti, 2018; Yang \& Li, 2017).

Under low R:FR, SA- and JA-mediated pathogen defense responses are compromised. The decreased SAinduced resistance in low R:FR is associated with an inhibition of SA-responsive kinases. Especially NPR1, representing an important transcriptional regulator positively affecting SA-induced defense genes, is not phosphorylated during low R:FR, thereby inhibiting transcription of target genes (de Wit et al., 2013). Recently, it was shown that FR light affects JA content directly by diminishing the level of JA-Ile derivates in A. thalianasubjected to Spodoptera littoralis caterpillars (Fernandez-Milmanda et al., 2020). The authors identified a sulfotransferase (ST2a), whose activity is strongly upregulated by FR in a phyB/PIF-dependent manner, to be responsible for the reduction of the active JA pool and thus causing an attenuation of JA response upon FR illumination. FR light negatively affects the JA-controlled extra floral nectar secretion in lima bean (Phaseolus lunatus ; Radhika, Kost, Mithofer, and Boland, 2010). In shade-grown common milkweed (Asclepias syriaca), the JA burst following herbivore attack ofDanaus plexippus caterpillars was halved compared to plants grown in sun and the latex content decreased (Agrawal, Kearney, Hastings, \& Ramsey, 2012). Shade conditions also lower plant sensitivity to JA (Moreno, Tao, Chory, \& Ballare, 2009), resembling the repressive effect of SA on JA responses on the expression of defense genes such asERF1 and PDF1.2 (Kazan \& Manners, 2012; Pieterse, Leon-Reyes, Van der Ent, \& Van Wees, 2009; Verhage, van Wees, \& Pieterse, 2010). JA-regulated defense genes are induced by transcription factors like MYC2 which are repressed by JASMONATE ZIM DOMAIN10 (JAZ10). Under low R:FR ratios, or in phyB mutants, the stability of JAZ10 is enhanced resulting in weakened defense responses (Ballare, 2014; Leone, Keller, Cerrudo, \& Ballare, 2014). In addition, Cerrudo et al. (2012) revealed that functional JAZ10 is necessary for a reduced defense of Arabidopsis plants against B. cinerea infection under shade conditions. In low R:FR ratio, not only JAZ stability is improved, but also gibberellin (GA) activity is enhanced resulting in a reduction of DELLA functionality. As a consequence, JAZ proteins can interact with MYCs thereby preventing the transcription of target genes - a process which is normally prevented by DELLAs (Ballare, 2014; Hou, Lee, Xia, Yan, \& Yu, 2010; Navarro et al., 2008). This indicates that not only JA and SA, but also GA responds to shade and impacts defense responses in plants.

Together, the quest for light through shade-avoidance responses is prioritized over plant immune responses, as reviewed by Ballare (2014).

\section{CONCLUSIONS}

In this review, we have described that light acts itself as a stressor and in addition regulates the outcome of numerous other abiotic and biotic stress responses. Plants have evolved complex crosstalk between light signaling and the different stress response pathways to survive and be prepared for future stress events. For instance, shortening of the days during autumn releases the phyB-dependent inhibitory effect on $C B F$ gene induction upon cold thereby preparing plants for the coming winter (Figure 2). Light pretreatment may result in improved tolerance to different stresses. For example, thermotolerance is improved after pretreatment with light (Figure 3). Fluctuating light, as plants experience under sunfleck conditions, prepares them for following excessive light exposures (Figure 1). Not only light intensity, but also light quality affects stress responses of plants and different wavelengths might have different functions. Light of most wavelengths improves stress tolerance, but shade conditions have different effects on different stresses. A decreased R:FR ratio improves stress defense especially under drought stress (Figure 4) and cold stress (Figure 2), but under heat stress and during pathogen attack, plants prioritize growth instead of defense (Figure 5). In these cases plants often invest more in offspring than in defense mechanisms (Fernandez-Milmanda et al., 2020).

It is quite clear from the topics described above, that plants evolved mechanisms implementing light information into stress signaling pathways to improve their tolerance to stress. The increasing number of experimental work addressing this crosstalk suggests that this is a growing area of research which will lead 
in the future to many more insights in the role of light during plant responses to abiotic and biotic stresses.

\section{FIGURE LEGENDS}

\section{Figure 1. Signaling pathways involved in the response to light stress.}

Light stress in plants can be caused by excess light, prolongation of the photoperiod, fluctuating light or UV light. (A) Excess light stress results in photoinhibition and ROS production which are counteracted by the D1 repair cycle and ROS scavenging enzymes. Upon perception of excess light, high light (HL)-responsive genes are induced resulting in the accumulation of anthocyanins but also resulting in an upregulation of genes involved in D1 repair and ROS scavenging. A specific role for blue light and UV-B, through CRY1 and UVR8 via COP1/HY5 has been shown in the regulation of HL-responsive genes. Moreover, CRY1 itself, upon light perception, produces ROS by the interconversion of the flavin redox states caused by photoexcitation. Chloroplast avoidance movement mediated through PHOT2 also contributes to enhanced high light tolerance. (B) Fluctuating light results in PSI photoinhibition. To deal with fluctuating light, plants developed alternative cyclic electron transport forces (CEF), of which the PGR5-dependent CEF has a bigger role as the NDH-dependent CEF. Together with the Mehler and water-water cycle, these CEFs act as alternative electron sinks. All these mechanisms avoid PSI photoinhibition causing tolerance to fluctuating light. Only FR light is known to ameliorate the energy dissipation via NPQ in PSII. (C) Photoperiod stress is caused by a prolongation of the light period resulting in a stress syndrome characterized by ROS production, jasmonic acid (JA) accumulation and eventually programmed cell death (PCD). Both cytokinin (CK) and CCA1/LHY are negative regulators of photoperiod stress. Recurrent photoperiod stress events reduce the stress response to subsequent stresses. (D) To overcome UV stress, plants induce UV-Bresponsive genes, including genes encoding ROS scavenging enzymes, flavonols and CDP photolyases. The UV-B-responsive genes can be regulated via UVR8 and CRY1 in a COP1/HY5 dependent manner. The $\mathrm{CPD}$ photolyases can also be induced through phyB and phyA. Also, UV-C irradiance, perceived by phyA or phyB, results in an inhibition of PCD. For more detailed information about the different pathways, please refer to section 2. Abbreviations: B, blue light; R, red light; FR, far-red light; UV, ultraviolet light; ROS, reactive oxygen species; CPD, cyclobutene pyrimidine dimers; PS, photosystem; ASC, ascorbate; MDA, monodehydroascorbate; SOD, superoxide dismutase; PQ, plastoquinone; PC, plastocyanin; Fd, ferredoxin; cytb $_{6}$ f, cytochrome $b_{6} f$; NPQ; non-photochemical quenching.

\section{Figure 2. Signaling pathways involved in the crosstalk between light and cold acclimation.}

Upon cold temperatures, the circadian clock-regulated $C B F$ genes are induced resulting in cold acclimation. Upon light perception, HY5 is activated which induces the expression of anthocyanin biosynthesis and coldresponsive genes through the Z-box/LTRE thereby reducing reactive oxygen species (ROS) and results in cold acclimation. Changes in light quality (R:FR) are sensed by phyB which exists in an active PfrB and an inactive PrB form. Under high R:FR ratios ( $>1)$, PfrB represses $C B F$ gene expression, while low R:FR ratios $(<1)$ caused by e.g. increased twilight during autumn causes cold acclimation by decreasing the amount of active PfrB. PIF7 which represses $C B F$ gene expression is under control of TOC1, a central component of the circadian clock, and under the control of phyB. Under SD photoperiod, $C B F$ genes are strongly induced causing cold acclimation. Under warmer LD, PIF 4 and PIFr which are under the control of phyB are higher expressed resulting in an inhibition of $C B F$ gene expression. As days shorten, e.g. during autumn, this repression falls away resulting in cold acclimation. CBF proteins interact with phyB and PIF3 causing degradation of PIF1, 4 and 5 which releases COR genes from PIF repression. For more information concerning the different pathways, please refer to section 3.1. Abbreviations: R, red light; FR, far-red light, $\mathrm{SD}$, short day; LD, long day; ROS, reactive oxygen species; LTRE, low temperature responsive element.

\section{Figure 3. Light signaling pathways contributing to thermortolerance.}

High temperature causes the induction of heat shock transcription factors (TFs) which results in thermotolerance. Under influence of light, a chloroplast-to-nucleus signal contributes to the induction of heat shock TFs. Independent of this chloroplast signal, the increase in HsfA1 upon heat stress causes a phyB-dependent increase in APX2expression resulting in ROS detoxification. The different photoreceptors are also involved 
in acquiring thermotolerance. Especially phyB, which is a thermosensor, and PIF4 play a central role. Thermal reversion and low R:FR ratios result in an inactivation of phyB, thereby resolving its inhibitory effect on PIF4. In turn, PIF4 stimulates the expression of auxin biosynthesis genes to regulate morphological adaptations like hyponasty or petiole elongation contributing to thermotolerance. PIF4 is inhibited by UVR8 and CRY1 as well. Also, other PIFs are regulated by phyB affecting FAD expression and fatty acid desaturation. phyB also influences ELF3 abundance which blocks PIF4 activity in an evening clock-independent and -dependent pathway involving also LUX and ELF4, other components of the EC. Blue light perceived by phototropins results in stomatal opening and increased leaf cooling. For more information concerning the different pathways, please refer to section 3.2. Abbreviations: R, red light; FR, far-red light; B, blue light; UV, ultraviolet light; ROS, reactive oxygen species; TFs, transcription factors; HsfA1, heat shock factor protein A1, PIFs, phytochrome interacting factors; EC, evening complex, FAD, fatty acid desaturase .

Figure 4. Light signaling pathways contributing to drought tolerance.

Drought stress results in biosynthesis of ABA leading to ABA-dependent gene regulation causing drought tolerance. In addition, stomata close preventing water loss via transpiration. Under shade conditions (low $\mathrm{R}: \mathrm{FR}$ ratio), ABA biosynthesis is stimulated which results in the induction of ABA-induced gene expression causing drought tolerance. Low R:FR ratios also increase the sensitivity to ABA causing increased drought tolerance. Also, phyB acts on stomatal opening in a COP1- or PIF3/PIF4-dependent way to regulate stomatal closure. Blue light perceived by CRY1 and PHOT1/PHOT2 represses the inhibitory function of COP1 on stomatal opening resulting in closed stomata thereby increasing drought tolerance. For more information concerning the different pathways, please refer to section 4. Abbreviations: ABA, abscisic acid; $\mathrm{R}$, red light; FR, far-red light; B, blue light.

Figure 5. Signaling pathways involved in the crosstalk between light and biotic stress defense.

Plant responses to pathogen or herbivore attack are affected by light. During biotic stress defense, plants perceive and mediate light signals via chloroplasts or photoreceptors. The chloroplast redox status, especially the redox status of the plastoquinone (PQ) pool, influences the plant defense to pathogens. The functionality of chloroplasts plays an important role in mediating the plant hypersensitive response (HR). The chloroplastlocated calcium-sensing receptor CAS mediates calcium signals affecting biotic stress defense. In addition, CAS controls the accumulation of salicylic acid (SA). In Arabidopsis plants, SA levels are regulated by blue light via a CRY2/PHOT2-mediated and by red light via phytochrome-regulated pathways. CRY2 and PHOT2 negatively regulate COP1 which in turn regulates the stability of the R protein HRT (Hypersensitive Response to TCV), thereby influencing pathogen resistance. The homologous, phytochrome-regulated TFs FHY3 and FAR1 influence SA-induced defense by controlling HEMB1 expression. The plant SA content influences the protein kinase NPR1 which regulates the transcription of SA-induced defense genes, such as $P R 1$, representing a marker for systemic acquired resistance (SAR). CRY1 promotes $P R 1$ gene expression. During shade (low R:FR ratios), phosphorylation of NPR1 is inhibited which affects PR1 expression and SA-induced defense. Shade environments also attenuate jasmonic acid (JA)-induced defense. The Arabidopsis sulfotransferase ST2a which is regulated by PIFs and responsible for the formation of $\mathrm{HSO}_{4}-\mathrm{JA}$ thereby decreasing levels of active JA is upregulated under FR light conditions. The stability of JAZ proteins is enhanced during low R:FR ratios in a phyB-dependent manner leading to attenuated defense responses. In addition, gibberellin (GA) activity is enhanced during shade resulting in decreased DELLA protein functionality. DELLAs represent negative regulators of the shade avoidance syndrome (SAS) and are involved in preventing interaction of JAZ proteins with its targets. UV-B light perceived by the UVR8 receptor enhances sinapate production involved in biotic stress defense. For more information concerning the different pathways, please refer to section 5. Abbreviations: R, red light; FR, far-red light; B, blue light; UV, ultraviolet light; TFs, transcription factors.

\section{REFERENCES}

Abuelsoud, W., Cortleven, A., \& Schmulling, T. (2020). Photoperiod stress alters the cellular redox status and is associated with an increased peroxidase and decreased catalase activity. BioRxivdoi: 
https://doi.org/10.1101/2020.03.05.978270

Agati, G., Azzarello, E., Pollastri, S., \& Tattini, M. (2012). Flavonoids as antioxidants in plants: location and functional significance. Plant Sci . doi: https://doi.org/10.1016/j.plantsci.2012.07.014

Agrawal, A. A., Kearney, E. E., Hastings, A. P., \& Ramsey, T. E. (2012). Attenuation of the jasmonate burst, plant defensive traits, and resistance to specialist monarch caterpillars on shaded common milkweed (Asclepias syriaca ). J Chem Ecol, 38(7), 893-901.

Ahmad, M., \& Cashmore, A. R. (1993). HY4 gene of A. thaliana encodes a protein with characteristics of a blue-light photoreceptor. Nature, 366(6451), 162-166.

Ahres, M., Gierczik, K., Boldizsar, A., Vitamvas, P., \& Galiba, G. (2020). Temperature and Light-QualityDependent Regulation of Freezing Tolerance in Barley. Plants, 9(1), pii: E83.

Alonso-Blanco, C., Gomez-Mena, C., Llorente, F., Koornneef, M., Salinas, J., \& Martinez-Zapater, J. M. (2005). Genetic and molecular analyses of natural variation indicate CBF2 as a candidate gene for underlying a freezing tolerance quantitative trait locus in Arabidopsis.Plant Physiol, 139(3), 1304-1312

Amissah, L., Mohren, G. M., Kyereh, B., \& Poorter, L. (2015). The effects of drought and shade on the performance, morphology and physiology of Ghanaian tree species. PLoS One, 10(4), e0121004.

Anjum, N. A., Khan, N. A., Sofo, A., Baier, M., \& Kizek, R. (2016). Redox homeostasis managers in plants under environmental stresses.Front Environ Sci . doi: https://doi.org/10.3389/ fenvs.2016.00035

Apel, K., \& Hirt, H. (2004). Reactive oxygen species: metabolism, oxidative stress, and signal transduction. Annu Rev Plant Biol,55, 373-399.

Arico, D., Legris, M., Castro, L., Garcia, C. F., Laino, A., Casal, J. J., \& Mazzella, M. A. (2019). Neighbour signals perceived by phytochrome B increase thermotolerance in Arabidopsis. Plant Cell Environ, 42(9), 2554-2566.

Asada, K. (1999). THE WATER-WATER CYCLE IN CHLOROPLASTS: Scavenging of Active Oxygens and Dissipation of Excess Photons. Annu Rev Plant Physiol Plant Mol Biol , 50, 601-639.

Asghar, M. A., Duab, J., Jiang, H., Lia, Y., Sun, X., Shang, J., . . . Yang, W. (2020). Shade pretreatment enhanced drought resistance of soybean. Environ Exp Bot, 171, 103952.

Baena-Gonzalez, E., \& Aro, E. M. (2002). Biogenesis, assembly and turnover of photosystem II units. Philos Trans R Soc Lond B Biol Sci, 357 (1426), 1451-1459.

Balfagon, D., Sengupta, S., Gomez-Cadenas, A., Fritschi, F. B., Azad, R. K., Mittler, R., \& Zandalinas, S. I. (2019). Jasmonic Acid Is Required for Plant Acclimation to a Combination of High Light and Heat Stress.Plant Physiol, 181(4), 1668-1682.

Ballare, C. L. (2014). Light regulation of plant defense. Annu Rev Plant Biol, 65, 335-363.

Banerjee, R., Schleicher, E., Meier, S., Viana, R. M., Pokorny, R., Ahmad, M., . . . Batschauer, A. (2007). The signaling state of Arabidopsis cryptochrome 2 contains flavin semiquinone. J Biol Chem, 282(20), 14916-14922.

Boccalandro, H. E., Rugnone, M. L., Moreno, J. E., Ploschuk, E. L., Serna, L., Yanovsky, M. J., \& Casal, J. J. (2009). Phytochrome B enhances photosynthesis at the expense of water-use efficiency in Arabidopsis. Plant Physiol, 150(2), 1083-1092.

Bogre, L., Okresz, L., Henriques, R., \& Anthony, R. G. (2003). Growth signalling pathways in Arabidopsis and the AGC protein kinases. Trends Plant Sci, 8(9), 424-431.

Bouly, J. P., Schleicher, E., Dionisio-Sese, M., Vandenbussche, F., Van Der Straeten, D., Bakrim, N., . . . Ahmad, M. (2007). Cryptochrome blue light photoreceptors are activated through interconversion of flavin 
redox states. J Biol Chem, 282(13), 9383-9391.

Brelsford, C. C., Morales, L. O., Nezval, J., Kotilainen, T. K., Hartikainen, S. M., Aphalo, P. J., \& Robson, T. M. (2019). Do UV-A radiation and blue light during growth prime leaves to cope with acute high light in photoreceptor mutants of Arabidopsis thaliana ?Physiol Plant, 165(3), 537-554.

Britt, A. (2002). Repair of damaged bases. Arabidopsis Book, 1 , e0005. doi:10.1199/tab.0005

Brown, B. A., Cloix, C., Jiang, G. H., Kaiserli, E., Herzyk, P., Kliebenstein, D. J., \& Jenkins, G. I. (2005). A UV-B-specific signaling component orchestrates plant UV protection. Proc Natl Acad Sci U S A, 102(50), 18225-18230.

Brown, B. A., \& Jenkins, G. I. (2008). UV-B signaling pathways with different fluence-rate response profiles are distinguished in mature Arabidopsis leaf tissue by requirement for UVR8, HY5, and HYH.Plant Physiol, $146(2), 576-588$.

Canamero, R. C., Bakrim, N., Bouly, J. P., Garay, A., Dudkin, E. E., Habricot, Y., \& Ahmad, M. (2006). Cryptochrome photoreceptors cry1 and cry2 antagonistically regulate primary root elongation in Arabidopsis thaliana. Planta, 224(5), 995-1003.

Caputo, C., Rutitzky, M., \& Ballare, C. L. (2006). Solar ultraviolet-B radiation alters the attractiveness of Arabidopsis plants to diamondback moths (Plutella xylostella L.): impacts on oviposition and involvement of the jasmonic acid pathway. Oecologia, 149(1), 81-90.

Casal, J. J. (2013). Photoreceptor signaling networks in plant responses to shade. Annu Rev Plant Biol, 64, 403-427.

Cecchini, E., Geri, C., Love, A. J., Coupland, G., Covey, S. N., \& Milner, J. J. (2002). Mutations that delay flowering in Arabidopsis de-couple symptom response from cauliflower mosaic virus accumulation during infection. Mol Plant Pathol, 3(2), 81-90.

Cerrudo, I., Keller, M. M., Cargnel, M. D., Demkura, P. V., de Wit, M., Patitucci, M. S., . . . Ballare, C. L. (2012). Low red/far-red ratios reduce Arabidopsis resistance to Botrytis cinerea and jasmonate responses via a COI1-JAZ10-dependent, salicylic acid-independent mechanism. Plant Physiol, 158(4), 2042-2052.

Chandra-Shekara, A. C., Gupte, M., Navarre, D., Raina, S., Raina, R., Klessig, D., \& Kachroo, P. (2006). Light-dependent hypersensitive response and resistance signaling against Turnip Crinkle Virus in Arabidopsis. Plant J, 45(3), 320-334.

Chisholm, S. T., Coaker, G., Day, B., \& Staskawicz, B. J. (2006). Host-microbe interactions: shaping the evolution of the plant immune response. Cell, 124(4), 803-814.

Christie, J. M. (2007). Phototropin blue-light receptors. Annu Rev Plant Biol, 58, 21-45.

Christie, J. M., Blackwood, L., Petersen, J., \& Sullivan, S. (2015). Plant flavoprotein photoreceptors. Plant Cell Physiol, 56(3), 401-413.

Christie, J. M., Salomon, M., Nozue, K., Wada, M., \& Briggs, W. R. (1999). LOV (light, oxygen, or voltage) domains of the blue-light photoreceptor phototropin (nph1): binding sites for the chromophore flavin mononucleotide. Proc Natl Acad Sci U S A, 96(15), 8779-8783.

Conrath, U. (2006). Systemic acquired resistance. Plant Signal Behav, 1( 4), 179-184.

Consentino, L., Lambert, S., Martino, C., Jourdan, N., Bouchet, P. E., Witczak, J., . . . Ahmad, M. (2015). Blue-light dependent reactive oxygen species formation by Arabidopsis cryptochrome may define a novel evolutionarily conserved signaling mechanism. New Phytol, 206(4), 1450-1462.

Correll, M. J., Coveney, K. M., Raines, S. V., Mullen, J. L., Hangarter, R. P., \& Kiss, J. Z. (2003). Phytochromes play a role in phototropism and gravitropism in Arabidopsis roots. Adv Space Res, 31(10), 2203-2210. 
Danon, A., Coll, N. S., \& Apel, K. (2006). Cryptochrome-1-dependent execution of programmed cell death induced by singlet oxygen inArabidopsis thaliana . Proc Natl Acad Sci U S A, 103(45), 17036-17041.

Daszkowska-Golec, A., \& Szarejko, I. (2013). Open or close the gate - stomata action under the control of phytohormones in drought stress conditions. Front Plant Sci, 4, 138.

Davey, M. P., Susanti, N. I., Wargent, J. J., Findlay, J. E., Paul Quick, W., Paul, N. D., \& Jenkins, G. I. (2012). The UV-B photoreceptor UVR8 promotes photosynthetic efficiency in Arabidopsis thalianaexposed to elevated levels of UV-B. Photosynth Res, 114(2), 121-131.

de Wit, M., Spoel, S. H., Sanchez-Perez, G. F., Gommers, C. M. M., Pieterse, C. M. J., Voesenek, L., \& Pierik, R. (2013). Perception of low red:far-red ratio compromises both salicylic acid- and jasmonic acid-dependent pathogen defences in Arabidopsis. Plant J, 75(1), 90-103.

De Wit, P. (1997). Pathogen avirulence and plant resistance: a key role for recognition. Trends Plant Sci 2: 452-458. Trends in Plant Science, 2, 452-458.

De Wit, P. (2007). How plants recognize pathogens and defend themselves. Cellular and Molecular Life Sciences , 2726-2732.

Delprato, M. L., Krapp, A. R., \& Carrillo, N. (2015). Green Light to Plant Responses to Pathogens: The Role of Chloroplast Light-Dependent Signaling in Biotic Stress. Photochem Photobiol, 91(5), 1004-1011.

Demkura, P. V., \& Ballare, C. L. (2012). UVR8 mediates UV-B-induced Arabidopsis defense responses against Botrytis cinerea by controlling sinapate accumulation. Mol Plant, 5(3), 642-652.

Devlin, P. F., \& Kay, S. A. (2000). Cryptochromes are required for phytochrome signaling to the circadian clock but not for rhythmicity. Plant Cell, 12(12), 2499-2510.

Dickinson, P. J., Kumar, M., Martinho, C., Yoo, S. J., Lan, H., Artavanis, G., . . . Wigge, P. A. (2018). Chloroplast Signaling Gates Thermotolerance in Arabidopsis. Cell Rep, 22(7), 1657-1665.

Ding, L., Wang, S., Song, Z. T., Jiang, Y., Han, J. J., Lu, S. J., . . . Liu, J. X. (2018). Two B-Box Domain Proteins, BBX18 and BBX23, Interact with ELF3 and Regulate Thermomorphogenesis in Arabidopsis. Cell Rep, 25(7), 1718-1728 e1714.

Dong, M. A., Farre, E. M., \& Thomashow, M. F. (2011). Circadian clock-associated 1 and late elongated hypocotyl regulate expression of the C-repeat binding factor (CBF) pathway in Arabidopsis. Proc Natl Acad Sci U S A, 108(17), 7241-7246.

Edelman, M., \& Mattoo, A. K. (2008). D1-protein dynamics in photosystem II: the lingering enigma. Photosynth Res, 98(1-3), 609-620.

El-Esawi, M., Arthaut, L. D., Jourdan, N., d'Harlingue, A., Link, J., Martino, C. F., \& Ahmad, M. (2017). Blue-light induced biosynthesis of ROS contributes to the signaling mechanism of Arabidopsis cryptochrome.Sci Rep, 7(1), 13875.

Emiliani, J., Grotewold, E., Falcone Ferreyra, M. L., \& Casati, P. (2013). Flavonols protect Arabidopsis plants against UV-B deleterious effects. Mol Plant, 6(4), 1376-1379.

Escobar-Bravo, R., Klinkhamer, P. G., \& Leiss, K. A. (2017). Interactive Effects of UV-B Light with Abiotic Factors on Plant Growth and Chemistry, and Their Consequences for Defense against Arthropod Herbivores. Front Plant Sci, 8, 278.

Escobar Bravo, R., Chen, G., Grosser, K., Van Dam, N. M., Leiss, K. A., \& Klinkhamer, P. G. L. (2019). Ultraviolet radiation enhances salicylic acid-mediated defense signaling and resistance to Pseudomonas syringae DC3000 in a jasmonic acid-deficient tomato mutant. Plant Signal Behav, 14(4), e1581560.

Ezer, D., Jung, J. H., Lan, H., Biswas, S., Gregoire, L., Box, M. S., . . . Wigge, P. A. (2017). The evening complex coordinates environmental and endogenous signals in Arabidopsis. Nat Plants, 3, 17087. 
Fahad, S., Bajwa, A. A., Nazir, U., Anjum, S. A., Farooq, A., Zohaib, A., . . . Huang, J. (2017). Crop Production under Drought and Heat Stress: Plant Responses and Management Options. Front Plant Sci,8, 1147.

Favory, J. J., Stec, A., Gruber, H., Rizzini, L., Oravecz, A., Funk, M., . . . Ulm, R. (2009). Interaction of COP1 and UVR8 regulates UV-B-induced photomorphogenesis and stress acclimation in Arabidopsis. EMBO $J, 28(5), 591-601$.

Fernandez-Milmanda, G. L., Crocco, C. D., Reichelt, M., Mazza, C. A., Kollner, T. G., Zhang, T., . . . Ballare, C. L. (2020). A light-dependent molecular link between competition cues and defence responses in plants. Nat Plants, 6(3), 223-230.

Fowler, S. G., Cook, D., \& Thomashow, M. F. (2005). Low temperature induction of Arabidopsis CBF1, 2, and 3 is gated by the circadian clock.Plant Physiol, 137(3), 961-968.

Frank, M., Cortleven, A., Novak, O., \& Schmulling, T. (2020). Root-derived trans-zeatin cytokinin protects Arabidopsis plants against photoperiod stress. doi: https://doi.org/10.1101/2020.03.05.978221

Franklin, K. A., \& Whitelam, G. C. (2007a). Light-quality regulation of freezing tolerance in Arabidopsis thaliana . Nat Genet,39(11), 1410-1413.

Franklin, K. A., \& Whitelam, G. C. (2007b). Phytochrome a function in red light sensing. Plant Signal Behav, 2(5), 383-385.

Gallagher, S., Short, T. W., Ray, P. M., Pratt, L. H., \& Briggs, W. R. (1988). Light-mediated changes in two proteins found associated with plasma membrane fractions from pea stem sections. Proc Natl Acad Sci U $S$ A, 85(21), 8003-8007.

Ganguly, D. R., Crisp, P. A., Eichten, S. R., \& Pogson, B. J. (2018). Maintenance of pre-existing DNA methylation states through recurring excess-light stress. Plant Cell Environ, 41(7), 1657-1672.

Genoud, T., Buchala, A. J., Chua, N. H., \& Metraux, J. P. (2002). Phytochrome signalling modulates the SA-perceptive pathway in Arabidopsis. Plant J, 31(1), 87-95.

Gonzalez, C. V., Ibarra, S. E., Piccoli, P. N., Botto, J. F., \& Boccalandro, H. E. (2012). Phytochrome B increases drought tolerance by enhancing ABA sensitivity in Arabidopsis thaliana. Plant Cell Environ, 35(11), 1958-1968.

Griebel, T., \& Zeier, J. (2008). Light regulation and daytime dependency of inducible plant defenses in Arabidopsis: phytochrome signaling controls systemic acquired resistance rather than local defense. Plant Physiol, 147 (2), 790-801.

Guo, H., Yang, H., Mockler, T. C., \& Lin, C. (1998). Regulation of flowering time by Arabidopsis photoreceptors. Science, 279(5355), 1360-1363.

Guy, C., Kaplan, F., Kopka, J., Selbig, J., \& Hincha, D. K. (2008). Metabolomics of temperature stress. Physiol Plant, 132(2), 220-235.

Han, S. H., Park, Y. J., \& Park, C. M. (2019a). Light Primes the Thermally Induced Detoxification of Reactive Oxygen Species During Development of Thermotolerance in Arabidopsis. Plant Cell Physiol, 60(1), 230-241.

Han, S. H., Park, Y. J., \& Park, C. M. (2019b). Light priming of thermotolerance development in plants. Plant Signal Behav, 14(1), 1554469.

Harvaux, M., \& Kloppstech, K. (2001). The protective functions of carotenoid and flavonoid pigments against excess visible radiation at chilling temperature investigated in Arabidopsis npq and tt mutants.Planta, 213(6), 953-966. 
Hayes, S., Sharma, A., Fraser, D. P., Trevisan, M., Cragg-Barber, C. K., Tavridou, E., . . . Franklin, K. A. (2017). UV-B Perceived by the UVR8 Photoreceptor Inhibits Plant Thermomorphogenesis. Curr Biol,27(1), $120-127$.

He, Y., Li, Y., Cui, L., Xie, L., Zheng, C., Zhou, G., . . . Xie, X. (2016). Phytochrome B Negatively Affects Cold Tolerance by Regulating OsDREB1 Gene Expression through Phytochrome Interacting Factor-Like Protein OsPIL16 in Rice. Front Plant Sci, 7, 1963.

Hectors, K., Van Oevelen, S., Geuns, J., Guisez, Y., Jansen, M. A., \& Prinsen, E. (2014). Dynamic changes in plant secondary metabolites during UV acclimation in Arabidopsis thaliana . Physiol Plant, 152(2), 219-230.

Heijde, M., \& Ulm, R. (2013). Reversion of the Arabidopsis UV-B photoreceptor UVR8 to the homodimeric ground state. Proc Natl Acad Sci U S A, 110(3), 1113-1118.

Heil, M. (2009). Damaged-self recognition in plant herbivore defence. Trends Plant Sci, 14(7), 356-363.

Hideg, E., Jansen, M. A., \& Strid, A. (2013). UV-B exposure, ROS, and stress: inseparable companions or loosely linked associates? Trends Plant Sci, 18(2), 107-115.

Holt, N. E., Fleming, G. R., \& Niyogi, K. K. (2004). Toward an understanding of the mechanism of nonphotochemical quenching in green plants. Biochemistry, 43(26), 8281-8289.

Hou, X., Lee, L. Y., Xia, K., Yan, Y., \& Yu, H. (2010). DELLAs modulate jasmonate signaling via competitive binding to JAZs. Dev Cell, 19 (6), 884-894. doi:10.1016/j.devcel.2010.10.024

Huang, J., Zhao, X., \& Chory, J. (2019). The Arabidopsis Transcriptome Responds Specifically and Dynamically to High Light Stress. Cell Rep, 29(12), 4186-4199 e4183.

Ito, S., Song, Y. H., \& Imaizumi, T. (2012). LOV domain-containing F-box proteins: light-dependent protein degradation modules in Arabidopsis. Mol Plant, 5(3), 573-582.

Izaguirre, M. M., Mazza, C. A., Biondini, M., Baldwin, I. T., \& Ballare, C. L. (2006). Remote sensing of future competitors: impacts on plant defenses. Proc Natl Acad Sci U S A, 103(18), 7170-7174.

Jelenska, J., Yao, N., Vinatzer, B. A., Wright, C. M., Brodsky, J. L., \& Greenberg, J. T. (2007). A J domain virulence effector of Pseudomonas syringae remodels host chloroplasts and suppresses defenses. Curr Biol, 17(6), 499-508.

Jeong, R. D., Chandra-Shekara, A. C., Barman, S. R., Navarre, D., Klessig, D. F., Kachroo, A., \& Kachroo, P. (2010). Cryptochrome 2 and phototropin 2 regulate resistance protein-mediated viral defense by negatively regulating an E3 ubiquitin ligase. Proc Natl Acad Sci U S A, 107(30), 13538-13543.

Jeong, R. D., Kachroo, A., \& Kachroo, P. (2010). Blue light photoreceptors are required for the stability and function of a resistance protein mediating viral defense in Arabidopsis. Plant Signal Behav, 5(11), 1504-1509.

Jiang, B., Shi, Y., Peng, Y., Jia, Y., Yan, Y., Dong, X., . . . Yang, S. (2020). Cold-Induced CBF-PIF3 Interaction Enhances Freezing Tolerance by Stabilizing the phyB Thermosensor in Arabidopsis. Mol Plant . Doi:https//doi.org/10.1016/j.molp.2020.04.006

Jiang, B., Shi, Y., Zhang, X., Xin, X., Qi, L., Guo, H., . . . Yang, S. (2017). PIF3 is a negative regulator of the CBF pathway and freezing tolerance in Arabidopsis. Proc Natl Acad Sci U S A, 114(32), E6695-E6702.

Jones, J. D., \& Dangl, J. L. (2006). The plant immune system. Nature, 444(7117), 323-329.

Joshi, R., Wani, S. H., Singh, B., Bohra, A., Dar, Z. A., Lone, A. A., . . . Singla-Pareek, S. L. (2016). Transcription Factors and Plants Response to Drought Stress: Current Understanding and Future Directions. Front Plant Sci, 7, 1029.

Jourdan, N., Martino, C. F., El-Esawi, M., Witczak, J., Bouchet, P. E., d'Harlingue, A., \& Ahmad, M. (2015). Blue-light dependent ROS formation by Arabidopsis cryptochrome-2 may contribute toward its 
signaling role.Plant Signal Behav, 10(8), e1042647.

Jung, J. H., Domijan, M., Klose, C., Biswas, S., Ezer, D., Gao, M., . . . Wigge, P. A. (2016). Phytochromes function as thermosensors in Arabidopsis. Science, 354(6314), 886-889.

Kampinga, H. H., Brunsting, J. F., Stege, G. J., Burgman, P. W., \& Konings, A. W. (1995). Thermal protein denaturation and protein aggregation in cells made thermotolerant by various chemicals: role of heat shock proteins. Exp Cell Res, 219(2), 536-546.

Kang, C. Y., Lian, H. L., Wang, F. F., Huang, J. R., \& Yang, H. Q. (2009). Cryptochromes, phytochromes, and COP1 regulate light-controlled stomatal development in Arabidopsis. Plant Cell, 21(9), 2624-2641.

Kangasjarvi, S., Neukermans, J., Li, S., Aro, E. M., \& Noctor, G. (2012). Photosynthesis, photorespiration, and light signalling in defence responses. $J$ Exp Bot, 63(4), 1619-1636.

Karpinski, S., Gabrys, H., Mateo, A., Karpinska, B., \& Mullineaux, P. M. (2003). Light perception in plant disease defence signalling. Curr Opin Plant Biol, 6(4), 390-396.

Kazan, K., \& Manners, J. M. (2011). The interplay between light and jasmonate signalling during defence and development. J Exp Bot,62(12), 4087-4100.

Kazan, K., \& Manners, J. M. (2012). JAZ repressors and the orchestration of phytohormone crosstalk. Trends Plant Sci, 17(1), 22-31.

Kiba, T., Henriques, R., Sakakibara, H., \& Chua, N. H. (2007). Targeted degradation of PSEUDORESPONSE REGULATOR5 by an SCFZTL complex regulates clock function and photomorphogenesis in Arabidopsis thaliana .Plant Cell, 19(8), 2516-2530.

Kidokoro, S., Maruyama, K., Nakashima, K., Imura, Y., Narusaka, Y., Shinwari, Z. K., . . . YamaguchiShinozaki, K. (2009). The phytochrome-interacting factor PIF7 negatively regulates DREB1 expression under circadian control in Arabidopsis. Plant Physiol,151(4), 2046-2057.

Kim, H. J., Kim, Y. K., Park, J. Y., \& Kim, J. (2002). Light signalling mediated by phytochrome plays an important role in cold-induced gene expression through the C-repeat/dehydration responsive element (C/DRE) in Arabidopsis thaliana . Plant Journal, 29(6), 693-704.

Kim, J. S., Mizoi, J., Kidokoro, S., Maruyama, K., Nakajima, J., Nakashima, K., . . . Yamaguchi-Shinozaki, K. (2012). Arabidopsis growth-regulating factor7 functions as a transcriptional repressor of abscisic acidand osmotic stress-responsive genes, including DREB2A . Plant Cell, 24(8), 3393-3405.

Kleine, T., Kindgren, P., Benedict, C., Hendrickson, L., \& Strand, A. (2007). Genome-wide gene expression analysis reveals a critical role for CRYPTOCHROME1 in the response of Arabidopsis to high irradiance.Plant Physiol, 144(3), 1391-1406.

Kliebenstein, D. J., Lim, J. E., Landry, L. G., \& Last, R. L. (2002). Arabidopsis UVR8 regulates ultraviolet-B signal transduction and tolerance and contains sequence similarity to human regulator of chromatin condensation 1. Plant Physiol, 130(1), 234-243.

Koini, M. A., Alvey, L., Allen, T., Tilley, C. A., Harberd, N. P., Whitelam, G. C., \& Franklin, K. A. (2009). High temperature-mediated adaptations in plant architecture require the bHLH transcription factor PIF4. Curr Biol, 19(5), 408-413.

Kono, M., Noguchi, K., \& Terashima, I. (2014). Roles of the cyclic electron flow around PSI (CEF-PSI) and $\mathrm{O}(2)$-dependent alternative pathways in regulation of the photosynthetic electron flow in short-term fluctuating light in Arabidopsis thaliana. Plant Cell Physiol,55(5), 990-1004.

Kono, M., \& Terashima, I. (2014). Long-term and short-term responses of the photosynthetic electron transport to fluctuating light. J Photochem Photobiol B, 137, 89-99. 
Kono, M., \& Terashima, I. (2016). Elucidation of Photoprotective Mechanisms of PSI Against Fluctuating Light photoinhibition. Plant Cell Physiol, 57(7), 1405-1414.

Kono, M., Yamori, W., Suzuki, Y., \& Terashima, I. (2017). Photoprotection of PSI by Far-Red Light Against the Fluctuating Light-Induced Photoinhibition in Arabidopsis thaliana and Field-Grown Plants. Plant Cell Physiol, 58(1), 35-45.

Kostaki, K. I., Coupel-Ledru, A., Bonnell, V. C., Gustavsson, M., Sun, P., McLaughlin, F. J., . . . Franklin, K. A. (2020). Guard Cells Integrate Light and Temperature Signals to Control Stomatal Aperture.Plant Physiol, 182(3), 1404-1419.

Kudoh, H., \& Sonoike, K. (2002). Irreversible damage to photosystem I by chilling in the light: cause of the degradation of chlorophyll after returning to normal growth temperature. Planta, 215(4), 541-548.

Larkindale, J., Hall, J. D., Knight, M. R., \& Vierling, E. (2005). Heat stress phenotypes of Arabidopsis mutants implicate multiple signaling pathways in the acquisition of thermotolerance. Plant Physiol,138(2), 882-897.

Larkindale, J., \& Knight, M. R. (2002). Protection against heat stress-induced oxidative damage in Arabidopsis involves calcium, abscisic acid, ethylene, and salicylic acid. Plant Physiol,128(2), 682-695.

Larkindale, J., \& Vierling, E. (2008). Core genome responses involved in acclimation to high temperature. Plant Physiol, 146(2), 748-761.

Lau, O. S., \& Deng, X. W. (2010). Plant hormone signaling lightens up: integrators of light and hormones. Curr Opin Plant Biol, 13(5), 571-577.

Lee, C. M., \& Thomashow, M. F. (2012). Photoperiodic regulation of the C-repeat binding factor (CBF) cold acclimation pathway and freezing tolerance in Arabidopsis thaliana . Proc Natl Acad Sci U S A, 109(37), 15054-15059.

Legris, M., Klose, C., Burgie, E. S., Rojas, C. C., Neme, M., Hiltbrunner, A., . . . Casal, J. J. (2016). Phytochrome B integrates light and temperature signals in Arabidopsis. Science, 354(6314), 897-900.

Leone, M., Keller, M. M., Cerrudo, I., \& Ballare, C. L. (2014). To grow or defend? Low red : far-red ratios reduce jasmonate sensitivity in Arabidopsis seedlings by promoting DELLA degradation and increasing JAZ10 stability. New Phytol, 204(2), 355-367.

Levitt, J. (1980). Responses of plants to environmental stresses.

Li, B., Gao, K., Ren, H., \& Tang, W. (2018). Molecular mechanisms governing plant responses to high temperatures. J Integr Plant Biol, 60(9), 757-779.

Li, J., Li, G., Wang, H., \& Wang Deng, X. (2011). Phytochrome signaling mechanisms. Arabidopsis Book, 9, e0148.

Li, N., Teranishi, M., Yamaguchi, H., Matsushita, T., Watahiki, M. K., Tsuge, T., . . . Hidema, J. (2015). UV-B-Induced CPD Photolyase Gene Expression is Regulated by UVR8-Dependent and -Independent Pathways in Arabidopsis. Plant Cell Physiol, 56(10), 2014-2023.

Liang, T., Mei, S., Shi, C., Yang, Y., Peng, Y., Ma, L., . . . Liu, H. (2018). UVR8 Interacts with BES1 and BIM1 to Regulate Transcription and Photomorphogenesis in Arabidopsis. Dev Cell, 44(4), 512-523 e515.

Lin, C. (2000). Photoreceptors and regulation of flowering time.Plant Physiol, 123(1), 39-50.

Liu, H., Liu, B., Zhao, C., Pepper, M., \& Lin, C. (2011). The action mechanisms of plant cryptochromes. Trends Plant Sci, 16(12), 684-691.

Liu, H., Yu, X., Li, K., Klejnot, J., Yang, H., Lisiero, D., \& Lin, C. (2008). Photoexcited CRY2 interacts with CIB1 to regulate transcription and floral initiation in Arabidopsis. Science, 322(5907), 1535-1539. 
Liu, Z., Zhang, Y., Wang, J., Li, P., Zhao, C., Chen, Y., \& Bi, Y. (2015). Phytochrome-interacting factors PIF4 and PIF5 negatively regulate anthocyanin biosynthesis under red light in Arabidopsis seedlings. Plant Sci, 238, 64-72.

Ma, D., Li, X., Guo, Y., Chu, J., Fang, S., Yan, C., . . . Liu, H. (2016). Cryptochrome 1 interacts with PIF4 to regulate high temperature-mediated hypocotyl elongation in response to blue light.Proc Natl Acad Sci U S A, 113(1), 224-229.

Mahmood, T., Khalid, S., Abdullah, M., Ahmed, Z., Shah, M. K. N., Ghafoor, A., \& Du, X. (2019). Insights into Drought Stress Signaling in Plants and the Molecular Genetic Basis of Cotton Drought Tolerance.Cells, $9(1)$.

Maier, A., \& Hoecker, U. (2015). COP1/SPA ubiquitin ligase complexes repress anthocyanin accumulation under low light and high light conditions. Plant Signal Behav, 10(1), e970440.

Malhotra, K., Kim, S. T., Batschauer, A., Dawut, L., \& Sancar, A. (1995). Putative blue-light photoreceptors from Arabidopsis thaliana and Sinapis alba with a high degree of sequence homology to DNA photolyase contain the two photolyase cofactors but lack DNA repair activity.Biochemistry, 34(20), 6892-6899.

Mao, J., Zhang, Y. C., Sang, Y., Li, Q. H., \& Yang, H. Q. (2005). From The Cover: A role for Arabidopsis cryptochromes and COP1 in the regulation of stomatal opening. Proc Natl Acad Sci U S A,102(34), 1227012275 .

Mas, P., Kim, W. Y., Somers, D. E., \& Kay, S. A. (2003). Targeted degradation of TOC1 by ZTL modulates circadian function in Arabidopsis thaliana. Nature, 426(6966), 567-570.

Matthews, J. S. A., Vialet-Chabrand, S., \& Lawson, T. (2020). Role of blue and red light in stomatal dynamic behaviour. J Exp Bot,71(7), 2253-2269.

Mittler, R., Finka, A., \& Goloubinoff, P. (2012). How do plants feel the heat? Trends Biochem Sci, 37 (3), $118-125$.

Mittler, R., Vanderauwera, S., Gollery, M., \& Van Breusegem, F. (2004). Reactive oxygen gene network of plants. Trends Plant Sci, 9(10), 490-498.

Moreno, J. E., Tao, Y., Chory, J., \& Ballare, C. L. (2009). Ecological modulation of plant defense via phytochrome control of jasmonate sensitivity. Proc Natl Acad Sci U S A, 106(12), 4935-4940.

Muller-Xing, R., Xing, Q., \& Goodrich, J. (2014). Footprints of the sun: memory of UV and light stress in plants. Front Plant Sci, 5, 474.

Munekage, Y., Hojo, M., Meurer, J., Endo, T., Tasaka, M., \& Shikanai, T. (2002). PGR5 is involved in cyclic electron flow around photosystem I and is essential for photoprotection in Arabidopsis. Cell,110(3), 361-371.

Murata, N., Takahashi, S., Nishiyama, Y., \& Allakhverdiev, S. I. (2007). Photoinhibition of photosystem II under environmental stress.Biochim Biophys Acta, 1767(6), 414-421.

Nagy, F., \& Schafer, E. (2002). Phytochromes control photomorphogenesis by differentially regulated, interacting signaling pathways in higher plants. Annu Rev Plant Biol, 53, 329-355.

Nakashima, K., Yamaguchi-Shinozaki, K., \& Shinozaki, K. (2014). The transcriptional regulatory network in the drought response and its crosstalk in abiotic stress responses including drought, cold, and heat.Front Plant Sci, 5, 170.

Navarro, L., Bari, R., Achard, P., Lison, P., Nemri, A., Harberd, N. P., \& Jones, J. D. (2008). DELLAs control plant immune responses by modulating the balance of jasmonic acid and salicylic acid signaling. Curr Biol, 18(9), 650-655. 
Nieto, C., Lopez-Salmeron, V., Daviere, J. M., \& Prat, S. (2015). ELF3-PIF4 interaction regulates plant growth independently of the Evening Complex. Curr Biol, 25(2), 187-193.

Nitschke, S., Cortleven, A., Iven, T., Feussner, I., Havaux, M., Riefler, M., \& Schmulling, T. (2016). Circadian Stress Regimes Affect the Circadian Clock and Cause Jasmonic Acid-Dependent Cell Death in Cytokinin-Deficient Arabidopsis Plants. Plant Cell, 28(7), 1616-1639.

Nitschke, S., Cortleven, A., \& Schmulling, T. (2017). Novel Stress in Plants by Altering the Photoperiod. Trends Plant Sci, 22 (11), 913-916.

Nomura, H., Komori, T., Uemura, S., Kanda, Y., Shimotani, K., Nakai, K., . . . Shiina, T. (2012). Chloroplast-mediated activation of plant immune signalling in Arabidopsis. Nat Commun, 3, 926.

Ohnishi, N., Allakhverdiev, S. I., Takahashi, S., Higashi, S., Watanabe, M., Nishiyama, Y., \& Murata, N. (2005). Two-step mechanism of photodamage to photosystem II: step 1 occurs at the oxygen-evolving complex and step 2 occurs at the photochemical reaction center.Biochemistry, 44(23), 8494-8499.

Oikawa, K., Kasahara, M., Kiyosue, T., Kagawa, T., Suetsugu, N., Takahashi, F., . . . Wada, M. (2003). Chloroplast unusual positioning1 is essential for proper chloroplast positioning. Plant Cell,15(12), 2805-2815.

Outlaw, W. H. J. (2003). Integration of Cellular and Physiological Functions of Guard Cells. Critical Reviews in Plant Sciences,,22(6), 503-529.

Paik, I., \& Huq, E. (2019). Plant photoreceptors: Multi-functional sensory proteins and their signaling networks. Semin Cell Dev Biol, 92, 114-121.

Pareek, A., Khurana, A., Sharma, A. K., \& Kumar, R. (2017). An Overview of Signaling Regulons During Cold Stress Tolerance in Plants. Curr Genomics, 18(6), 498-511.

Pierik, R., \& de Wit, M. (2014). Shade avoidance: phytochrome signalling and other aboveground neighbour detection cues. J Exp Bot, 65(11), 2815-2824.

Pieterse, C. M., Leon-Reyes, A., Van der Ent, S., \& Van Wees, S. C. (2009). Networking by small-molecule hormones in plant immunity. Nat Chem Biol, 5(5), 308-316.

Pospisil, P. (2016). Production of Reactive Oxygen Species by Photosystem II as a Response to Light and Temperature Stress.Front Plant Sci, 7, 1950.

Qi, J., Zhang, M., Lu, C., Hettenhausen, C., Tan, Q., Cao, G., . . . Wu, J. (2018). Ultraviolet-B enhances the resistance of multiple plant species to lepidopteran insect herbivory through the jasmonic acid pathway. Sci Rep, 8(1), 277.

Radhika, V., Kost, C., Mithofer, A., \& Boland, W. (2010). Regulation of extrafloral nectar secretion by jasmonates in lima bean is light dependent. Proc Natl Acad Sci U S A, 107(40), 17228-17233.

Rai, N., Neugart, S., Yan, Y., Wang, F., Siipola, S. M., Lindfors, A. V., . . . Aphalo, P. J. (2019). How do cryptochromes and UVR8 interact in natural and simulated sunlight? $J$ Exp Bot, 70(18), 4975-4990.

Rizzini, L., Favory, J. J., Cloix, C., Faggionato, D., O'Hara, A., Kaiserli, E., . . . Ulm, R. (2011). Perception of UV-B by the Arabidopsis UVR8 protein. Science, 332(6025), 103-106.

Roberts, M. R., \& Paul, N. D. (2006). Seduced by the dark side: integrating molecular and ecological perspectives on the influence of light on plant defence against pests and pathogens. New Phytol,170(4), 677-699.

Roden, L. C., \& Ingle, R. A. (2009). Lights, rhythms, infection: the role of light and the circadian clock in determining the outcome of plant-pathogen interactions. Plant Cell, 21(9), 2546-2552.

Rodriguez-Herva, J. J., Gonzalez-Melendi, P., Cuartas-Lanza, R., Antunez-Lamas, M., Rio-Alvarez, I., Li, Z., . . . Lopez-Solanilla, E. (2012). A bacterial cysteine protease effector protein interferes with photosynthesis 
to suppress plant innate immune responses. Cell Microbiol, 14(5), 669-681.

Sangwan, V., Orvar, B. L., Beyerly, J., Hirt, H., \& Dhindsa, R. S. (2002). Opposite changes in membrane fluidity mimic cold and heat stress activation of distinct plant MAP kinase pathways. Plant J, 31(5), 629-638.

Sato, R., Kono, M., Harada, K., Ohta, H., Takaichi, S., \& Masuda, S. (2017). FLUCTUATING-LIGHTACCLIMATION PROTEIN1, Conserved in Oxygenic Phototrophs, Regulates H+ Homeostasis and NonPhotochemical Quenching in Chloroplasts. Plant Cell Physiol, 58(10), 1622-1630.

Schneider, T., Bolger, A., Zeier, J., Preiskowski, S., Benes, V., Trenkamp, S., . . . Matsubara, S. (2019). Fluctuating Light Interacts with Time of Day and Leaf Development Stage to Reprogram Gene Expression. Plant Physiol, 179(4), 1632-1657.

Schreiber, U., Hormann, H., Asada, K., \& Neubauer, C. (1995). O2-dependent electron flow in spinach chloroplasts: properties and possible regulaion of the Mehler-ascorbate peroxidase cycle.Photosynthesis, 2, 813-818.

Sessa, G., Carabelli, M., Possenti, M., Morelli, G., \& Ruberti, I. (2018). Multiple Pathways in the Control of the Shade Avoidance Response. Plants (Basel), 7(4).

Shamrai, S. N. (2014). Plant immune system: Basal immunity. Cytology and Genetics, 48, 258-271.

Shikanai, T. (2007). Cyclic electron transport around photosystem I: genetic approaches. Annu Rev Plant Biol, 58, 199-217.

Shikanai, T. (2016). Chloroplast NDH: a different enzyme with a structure similar to that of respiratory NADH dehydrogenase.Biochim Biophys Acta, 7, 1015-1022.

Shin, D. H., Choi, M., Kim, K., Bang, G., Cho, M., Choi, S. B., . . . Park, Y. I. (2013). HY5 regulates anthocyanin biosynthesis by inducing the transcriptional activation of the MYB75/PAP1 transcription factor in Arabidopsis. FEBS Lett, 587(10), 1543-1547.

Silva, C. S., Nayak, A., Lai, X., Hutin, S., Hugouvieux, V., Jung, J. H., . . . Zubieta, C. (2020). Molecular mechanisms of Evening Complex activity in Arabidopsis. Proc Natl Acad Sci U S A, 117(12), 6901-6909.

Soitamo, A. J., Piippo, M., Allahverdiyeva, Y., Battchikova, N., \& Aro, E. M. (2008). Light has a specific role in modulating Arabidopsis gene expression at low temperature. BMC Plant Biol, 8, 13.

Somers, D. E., Devlin, P. F., \& Kay, S. A. (1998). Phytochromes and cryptochromes in the entrainment of the Arabidopsis circadian clock.Science, 282(5393), 1488-1490.

Somers, D. E., Schultz, T. F., Milnamow, M., \& Kay, S. A. (2000). ZEITLUPE encodes a novel clockassociated PAS protein from Arabidopsis. Cell, 101(3), 319-329.

Song, J., Liu, Q., Hu, B., \& Wu, W. (2017). Photoreceptor PhyB Involved in Arabidopsis Temperature Perception and Heat-Tolerance Formation.Int J Mol Sci, 18(6).

Song, L., Jiang, Y., Zhao, H., \& Hou, M. (2012). Acquired thermotolerance in plants. Plant Cell Tiss Organ Cult, 111, 265-276.

Song, Y. H., Estrada, D. A., Johnson, R. S., Kim, S. K., Lee, S. Y., MacCoss, M. J., \& Imaizumi, T. (2014). Distinct roles of FKF1, Gigantea, and Zeitlupe proteins in the regulation of Constans stability in Arabidopsis photoperiodic flowering. Proc Natl Acad Sci U S A,111(49), 17672-17677.

Sonoike, K. (1996). Photoinhibition of Photosystem I: Its Physiological Significance in the Chilling Sensitivity of Plants. Plant and Cell Physiology, 37(3), 239-247.

Sonoike, K., \& Terashima, I. (1994). Mechanism of photosystem-I photoinhibition in leaves of Cucumis sativus L.. . Planta, 194 , 287-293. doi:doi.org/10.1007/BF01101690 
Takahashi, S., \& Badger, M. R. (2011). Photoprotection in plants: a new light on photosystem II damage. Trends Plant Sci, 16(1), 53-60.

Takahashi, S., Milward, S. E., Yamori, W., Evans, J. R., Hillier, W., \& Badger, M. R. (2010). The solar action spectrum of photosystem II damage. Plant Physiol, 153(3), 988-993.

Takahashi, S., \& Murata, N. (2008). How do environmental stresses accelerate photoinhibition? Trends Plant Sci, 13(4), 178-182.

Takase, T., Nishiyama, Y., Tanihigashi, H., Ogura, Y., Miyazaki, Y., Yamada, Y., \& Kiyosue, T. (2011). LOV KELCH PROTEIN2 and ZEITLUPE repress Arabidopsis photoperiodic flowering under non-inductive conditions, dependent on FLAVIN-BINDING KELCH REPEAT F-BOX1. Plant J, 67(4), 608-621.

Tallman, G. (2004). Are diurnal patterns of stomatal movement the result of alternating metabolism of endogenous guard cell $\mathrm{ABA}$ and accumulation of $\mathrm{ABA}$ delivered to the apoplast around guard cells by transpiration? J Exp Bot, 55(405), 1963-1976.

Taylor, B. L., \& Zhulin, I. B. (1999). PAS domains: internal sensors of oxygen, redox potential, and light. Microbiol Mol Biol Rev,63(2), 479-506.

Thomashow, M. F. (1999). PLANT COLD ACCLIMATION: Freezing Tolerance Genes and Regulatory Mechanisms. Annu Rev Plant Physiol Plant Mol Biol, 50, 571-599.

Thomashow, M. F. (2010). Molecular basis of plant cold acclimation: insights gained from studying the CBF cold response pathway. Plant Physiol, 154(2), 571-577.

Tissot, N., \& Ulm, R. (2020). Cryptochrome-mediated blue-light signalling modulates UVR8 photoreceptor activity and contributes to UV-B tolerance in Arabidopsis. Nat Commun, 11 (1), 1323.

Torres, M. A. (2010). ROS in biotic interactions. Physiol Plant, 138 (4), 414-429.

Trotta, A., Rahikainen, M., Konert, G., Finazzi, G., \& Kangasjarvi, S. (2014). Signalling crosstalk in light stress and immune reactions in plants. Philos Trans R Soc Lond B Biol Sci, 369(1640), 20130235.

Tsuda, K., \& Katagiri, F. (2010). Comparing signaling mechanisms engaged in pattern-triggeredand effectortriggered immunity. Current Opinion in Plant Biology, 13, 459-465.

Verhage, A., van Wees, S. C., \& Pieterse, C. M. (2010). Plant immunity: it's the hormones talking, but what do they say? Plant Physiol,154(2), 536-540.

Wang, F., Guo, Z., Li, H., Wang, M., Onac, E., Zhou, J., . . . Zhou, Y. (2016). Phytochrome A and B Function Antagonistically to Regulate Cold Tolerance via Abscisic Acid-Dependent Jasmonate Signaling. Plant Physiol, 170(1), 459-471.

Wang, F. F., Lian, H. L., Kang, C. Y., \& Yang, H. Q. (2010). Phytochrome B is involved in mediating red light-induced stomatal opening in Arabidopsis thaliana. Mol Plant, 3(1), 246-259.

Wang, Q., \& Lin, C. (2020). Mechanisms of Cryptochrome-Mediated Photoresponses in Plants. Annu Rev Plant Biol . Doi://https/doi.org/10.1146/annurev-arplant-050718-100300

Yamamoto, Y. (2016). Quality Control of Photosystem II: The Mechanisms for Avoidance and Tolerance of Light and Heat Stresses are Closely Linked to Membrane Fluidity of the Thylakoids. Front Plant Sci,7, 1136.

Yang, C., \& Li, L. (2017). Hormonal Regulation in Shade Avoidance.Front Plant Sci, 8, 1527.

Yang, Y., Zhang, L., Chen, P., Liang, T., Li, X., \& Liu, H. (2020). UV-B photoreceptor UVR8 interacts with MYB73/MYB77 to regulate auxin responses and lateral root development. EMBO J, 39(2), e101928. 
Yang, Y. X., Wang, M. M., Yin, Y. L., Onac, E., Zhou, G. F., Peng, S., . . . Zhou, Y. H. (2015). RNA-seq analysis reveals the role of red light in resistance against Pseudomonas syringae pv. tomato DC3000 in tomato plants. BMC Genomics, 16, 120.

Yi, C., \& Deng, X. W. (2005). COP1 - from plant photomorphogenesis to mammalian tumorigenesis. Trends Cell Biol, 15(11), 618-625.

Yin, R. (2017). Cooling Down Thermomorphogenesis by UV-B Signaling. Trends Plant Sci, 22(6), 447-449.

Yoshinaga, N., Alborn, H. T., Nakanishi, T., Suckling, D. M., Nishida, R., Tumlinson, J. H., \& Mori, N. (2010). Fatty acid-amino acid conjugates diversification in lepidopteran caterpillars. J Chem Ecol, 36(3), 319-325.

Yu, X., Klejnot, J., Zhao, X., Shalitin, D., Maymon, M., Yang, H., . . . Lin, C. (2007). Arabidopsis cryptochrome 2 completes its posttranslational life cycle in the nucleus. Plant Cell, 19(10), 3146-3156.

Zeier, J., Pink, B., Mueller, M. J., \& Berger, S. (2004). Light conditions influence specific defence responses in incompatible plant-pathogen interactions: uncoupling systemic resistance from salicylic acid and PR1 accumulation. Planta, 219(4), 673-683.

Zhang, M., Chiang, Y. H., Toruno, T. Y., Lee, D., Ma, M., Liang, X., . . . Coaker, G. (2018). The MAP4 Kinase SIK1 Ensures Robust Extracellular ROS Burst and Antibacterial Immunity in Plants. Cell Host Microbe, 24(3), 379-391 e375. 


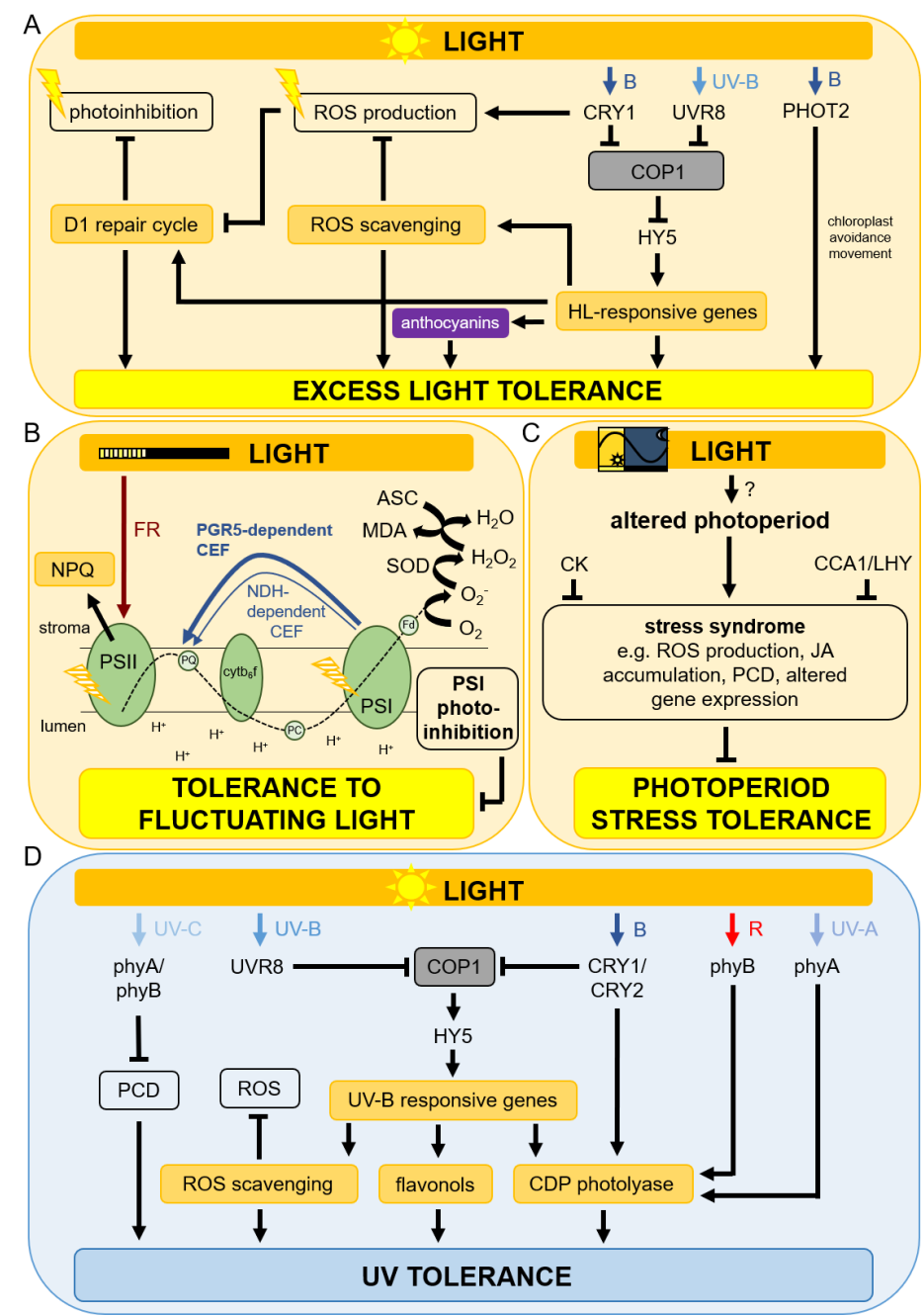

Figure 1. Signaling pathways involved in the response to light stress. 
Information box. Key facts about the roles of light and photoreceptors in response to abiotic and biotic stresses

Excess light stress

PHOT2 is essential for the chloroplast avoidance movement to reduce the intensity of inciden

light

CRY1 is vital for the induction of transcription of excess light responsive genes and anthocyanin biosynthesis acting through COP1 and HY5

Fluctuating light stress

far-red light has a positive effect on photosynthesis thereby accelerating NPQ relaxation

Photoperiod stress

- the role of photoreceptors is not yet known

UV stress

phyA, phyB, CRY1, CRY2 and UVR8 regulate the transcription of CPD photolyase genes

a HY5/COP1/UVR8- or CRY1/CRY2-dependent pathway mediates the production of UV protective compounds

Cold stress

phyB represses the CBF pathway in PIF-dependent and -independent ways reducing cold acclimation

under long day conditions, cold acclimation is repressed in a phyB/PIF4/PIF7-dependent way HY5 stimulates the expression of anthocyanin biosynthesis and cold responsive genes independent of COP1

Heat stress

a light-induced chloroplast-to-nucleus signal primes plants for increased thermotolerance light primes HsfA1-mediated induction of APX2 expression in a phyB-dependent but PIFindependent manner

Drought stress

CRY1, phototropins and phyB regulate stomatal opening in a COP1-dependent way and phyB, in addition, in a PIF3/PIF4-dependent way

low R:FR ratios (shade conditions) increase ABA sensitivity and thereby drought tolerance

Biotic stress

light intensity, quality and duration are of crucial importance for the activation of the full immune response in plant - pathogen interactions

both photoreceptors and chloroplasts mediate light signals in plant-pathogen defense both photo
responses

- phyA, phyB and CRY1 and PHOT2 contribute to systemic acquired resistance 